\title{
Effects of $\alpha$-Mangostin Derivatives on the Alzheimer's Disease Model of Rats and Their Mechanism: A Combination of Experimental Study and Computational Systems Pharmacology Analysis
}

Yan Chen, " Yuemin Bian," Jian-Wei Wang, Ting-Ting Gong, You-Min Ying, Lie-Feng Ma, Wei-Guang Shan, Xiang-Qun Xie, and Zha-Jun Zhan*

Cite This: ACS Omega 2020, 5, 9846-9863

Read Online

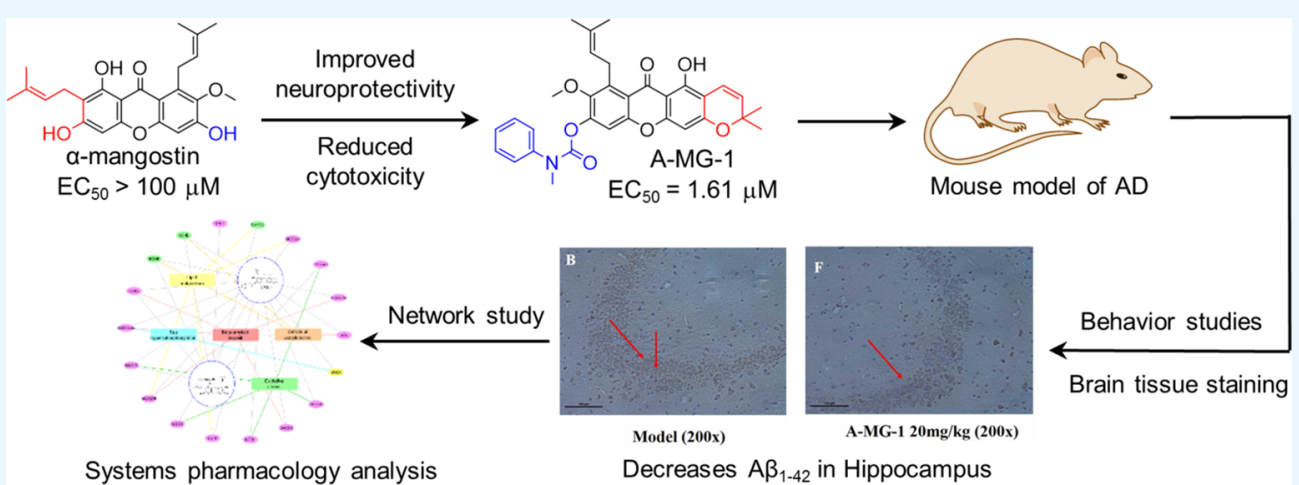

ABSTRACT: $\alpha$-Mangostin $(\alpha-\mathrm{M})$ is a natural xanthone from the pericarp of fruit Garcinia mangostana and possesses versatile biological activities. $\alpha-\mathrm{M}$ has a therapeutic potential to treat Alzheimer's disease (AD) because of its anti-inflammatory, antioxidative, and neuroprotective activities. However, the use of $\alpha-\mathrm{M}$ for $\mathrm{AD}$ treatment is limited due to its cytotoxic activities and relatively low potency. Modifications of its chemical structure were needed to reduce its cytotoxicity and improve its therapeutic potential against $\mathrm{AD}$. For this purpose, $16 \alpha-\mathrm{M}$ carbamate derivatives were synthesized. An animal model of AD was established, and the effects of AMG-1 on the spatial learning ability and memory ability were evaluated using behavioral tests. The effect on neuropathology was tested by histopathological evaluation, Nissl staining, and silver staining. Computational systems pharmacology analysis using the chemogenomics knowledgebase was applied for network studies. Compound-target, target-pathway, and target-disease networks were constructed, integrating both in silico analysis and reported experimental data. The results show that AMG-1 can demonstrate its therapeutic effects in a one-molecule, multiple-targets manner to remarkably ameliorate neurological changes and reverse behavioral deficits in $\mathrm{AD}$ model rats. The improved cognitive function and alleviated neuronal injury can be observed. The ability of AMG-1 to scavenge $\beta$-amyloid in the hippocampus was validated in $\mathrm{AD}$ model rats.

\section{INTRODUCTION}

Alzheimer's disease $(\mathrm{AD})$ is a neurodegenerative and psychiatric disorder. $\mathrm{AD}$ has become the most devastating disease worldwide, and its prevalence is expected to greatly increase over the next few decades as the population ages. ${ }^{1}$ The hallmarks of $\mathrm{AD}$ are cognitive deficit and memory impairments, which are caused by the massive loss of neurons and synapses. ${ }^{2}$ Accumulating evidence suggests that abnormally folded $\beta$-amyloid $(\mathrm{A} \beta)$ protein can be one of the important pathological contributors to neuronal loss in $\mathrm{AD} .^{3-5} \mathrm{~A} \beta$ plaques can result in oxidative stress, inflammation, and neurotoxicity, all of which can initiate the pathogenic cascade and ultimately lead to cognitive dysfunction. ${ }^{6-8}$ Thus, the strategy to increase the $\mathrm{A} \beta$ clearance is being actively pursued as a promising disease-modifying therapy. Currently, five drugs have been approved for the treatment of $\mathrm{AD}$. Four of them are acetylcholinesterase inhibitors (donepezil, tacrine, rivastigmine, and galantamine) and one $N$-methyl-D-aspartate (NMDA) receptor antagonist (memantine). ${ }^{9}$ Donepezil is usually considered as the first choice for $\mathrm{AD}$ patients' treatment. ${ }^{10}$ However, donepezil can only improve the cognition and behavior of the patients with $\mathrm{AD}$ but does not have any effect on slowing the progression or curing the disease. ${ }^{11}$ Besides, donepezil has many side effects, including

Received: January 5, 2020

Accepted: April 16, 2020

Published: April 23, 2020 
Scheme 1. Reagents and Conditions: (a) $\mathrm{CH}_{3} \mathrm{I}$ or $\mathrm{C}_{2} \mathrm{H}_{5} \mathrm{Br}, \mathrm{K}_{2} \mathrm{CO}_{3}$, Reflux, and $12 \mathrm{~h}$; (b) DDQ Toluene, $40{ }^{\circ} \mathrm{C}$, and 5 h; (c) BTC, $\mathrm{Et}_{3} \mathrm{~N}$, DMAP, DCM, rt, and $10 \mathrm{~h}$
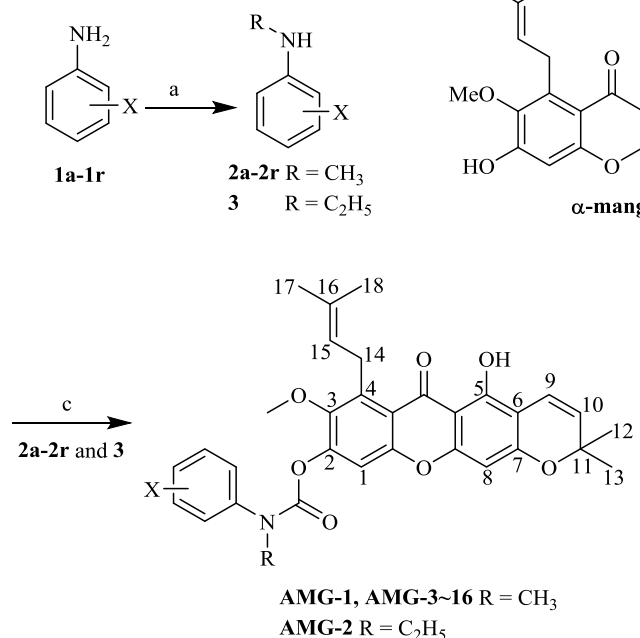

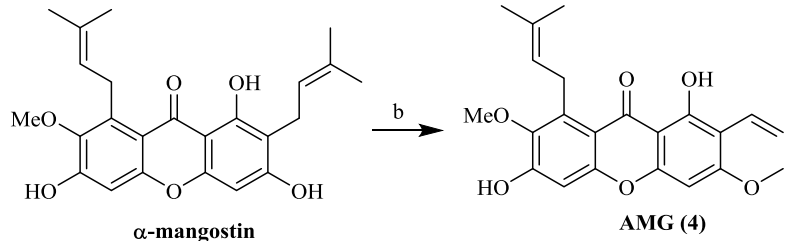

AMG-1 $\mathrm{X}=\mathrm{H} \quad$ AMG-1 $\mathrm{X}=\mathrm{H}$

AMG-3 X $=o$ - $\mathrm{CH}_{3}$ AMG-4, $\mathrm{X}=m$ - $\mathrm{CH}_{3}$

AMG-5 $\mathrm{X}=p-\mathrm{CH}_{3} \quad$ AMG-6 $\mathrm{X}=o-\mathrm{OCH}_{3}$

AMG-7 X $=m-\mathrm{OCH}_{3}$ AMG-8 $\mathrm{X}=p-\mathrm{OCH}_{3}$

AMG-9 $\mathrm{X}=m-\mathrm{C}_{2} \mathrm{H}_{5}$ AMG-10, $\mathrm{X}=m$-Cl

AMG-11 $\mathrm{X}=p$ - $\mathrm{Cl} \quad$ AMG-12 $\mathrm{X}=o-\mathrm{Br}$

AMG-13 X $=m$ - $\mathrm{Br} \quad$ AMG-14 $\mathrm{X}=p$ - $\mathrm{Br}$

AMG-15 $\mathrm{X}=p-\mathrm{C}_{4} \mathrm{H}_{9}$ AMG-16 $\mathrm{X}=m$-OEt

Table 1. 50\% Inhibitory Concentration $\left(\mathrm{IC}_{50}\right)$ of Derivatives against $\mathrm{AChE}$ and $50 \%$ Effective Concentration EC $\mathrm{En}_{50}$ on 12 Cells ${ }^{d}$

\begin{tabular}{|c|c|c|c|c|c|}
\hline compound & $\mathrm{IC}_{50}(\mu \mathrm{M})^{a}$ & $\mathrm{EC}_{50}(\mu \mathrm{M})^{b}$ & compound & $\mathrm{IC}_{50}(\mu \mathrm{M})^{a}$ & $\mathrm{EC}_{50}(\mu \mathrm{M})^{b}$ \\
\hline galantamine & $4.24 \pm 1.65$ & $\mathrm{ND}^{c}$ & AMG-7 & $43.45 \pm 5.27$ & $>100$ \\
\hline$\alpha-\mathrm{M}$ & $34.28 \pm 6.06$ & $>100$ & AMG-8 & $>100$ & $>100$ \\
\hline AMG & $41.21 \pm 6.28$ & $>100$ & AMG-9 & $45.97 \pm 15.32$ & $>100$ \\
\hline edaravone & $\mathrm{ND}^{c}$ & $69.98 \pm 5.73$ & AMG-10 & $47.78 \pm 16.78$ & $13.07 \pm 2.25$ \\
\hline AMG-1 & $52.55 \pm 11.27$ & $1.61 \pm 0.35$ & AMG-11 & $43.60 \pm 12.33$ & $12.33 \pm 4.65$ \\
\hline AMG-2 & $35.14 \pm 9.38$ & $12.77 \pm 4.23$ & AMG-12 & $19.20 \pm 6.87$ & $>100$ \\
\hline AMG-3 & $32.89 \pm 7.78$ & $13.36 \pm 5.17$ & AMG-13 & $15.07 \pm 3.56$ & $>100$ \\
\hline AMG-4 & $>100$ & $8.27 \pm 2.01$ & AMG-14 & $40.64 \pm 13.78$ & $>100$ \\
\hline AMG-5 & $>100$ & $>100$ & AMG-15 & $34.46 \pm 9.38$ & $>100$ \\
\hline AMG-6 & $>100$ & $>100$ & AMG-16 & $37.49 \pm 11.24$ & $>100$ \\
\hline
\end{tabular}

${ }^{a}$ Mean \pm standard error of the mean (SEM) of three experiments for $50 \%$ inhibition of AChE. ${ }^{b}$ Mean \pm SEM of three independent experiments for $50 \%$ antioxidant neuroprotective effect. ${ }^{c}$ Not determined. ${ }^{d}$ Inhibitory activity $\left(\mathrm{IC}_{50}, \mu \mathrm{M}\right)$ of AChE and neuroprotective effective concentration $\left(\mathrm{EC}_{50}, \mu \mathrm{M}\right)$ for the studied compounds, galantamine and edaravone.

loss of appetite, diarrhea, gastrointestinal upset, difficulty sleeping, vomiting, and muscle cramping, which further limits its application. ${ }^{12}$

Recently, the studies on active ingredients from natural products and medicinal herbs for treating $\mathrm{AD}$ have attracted substantial attention. ${ }^{13-15} \alpha$-Mangostin $(\alpha$-M, Scheme 1$)$ is a natural xanthone separated from the mangosteen pericarp. ${ }^{16} \alpha$ $\mathrm{M}$ has been reported to possess a wide spectrum of biological activities such as anti-inflammatory, cardioprotective, antitumor, antidiabetic, antibacterial, antifungal, antioxidant, antiparasitic, and antiobesity activities. ${ }^{17-26}$ Recent evidence further suggests that $\alpha$-M can inhibit amyloid aggregation. ${ }^{27}$ However, the major obstacles facing the application of $\alpha$-M are due to its cytotoxic activities, hydrophobic nature, and thus low bioavailability and accumulation in the target organs. To decrease its cytotoxicity and improve the neuroprotective effect, we modified the structure of $\alpha$-M through the medicinal chemistry approach. The initial substrate $\alpha-\mathrm{M}$ was converted into the cyclized compound AMG (Scheme 1). Then, the hydroxyl at C-2 in AMG was reacted with different isocyanates to afford a series of $\alpha-\mathrm{M}$ carbamate derivatives.

Hence, one of the aims of our present work is to elucidate AChE inhibitory and neuroprotective effects of AMG derivatives in vitro. As a result, AMG-1, after structural optimization, has improved neuroprotective effects. To further investigate whether AMG-1 can improve the learning and memory of $\mathrm{AD}$ 's model of rats, we also induced an $\mathrm{AD}$-like rat model by injecting $\mathrm{A} \beta_{25-35}$ into the bilateral hippocampus of rats. At the same time, the molecular mechanism that underlies the experimental observations was further analyzed by computational systems pharmacology. ${ }^{28}$ Our study showed that AMG-1 not only protected rat cerebral hippocampal neurons against $\mathrm{A} \beta_{25-35}$ oligomer-induced $\beta$-amyloid deposition but also improved the learning and memory ability and alleviated neuronal injury by scavenging $\beta$-amyloid in the hippocampus of $\mathrm{AD}$ model rats.

\section{RESULTS}

Synthesis of AMG Derivatives. The preparation of the target compounds started from $\alpha-\mathrm{M}$ through four steps as described in Scheme 1. The prenyl group is an important factor for the retention of cytotoxicity in prenylated xanthones, ${ }^{29}$ so $\alpha$-M was cyclized to yield AMG (4) to reduce cytotoxicity. The methylation of substituted aniline (1a-1r) resulted in substituted $N$-methylaniline $(2 \mathbf{a}-2 \mathbf{r})$ and $N$ ethylaniline (3). The carbamoyl group has been proven to be an important pharmacophore of acetylcholinesterase inhibitory activity. ${ }^{30,31}$ Furthermore, carbamates could also 
affect the expression and processing of the $\mathrm{A} \beta$-precursor protein, one of the most important therapeutic goals in Alzheimer's disease. ${ }^{32}$ To improve the bioactivity of $\alpha$-M, the carbamoyl groups were then introduced into AMG (4) by reacting with chlorides $(3 \mathrm{a}-3 \mathbf{r})$ to afford $\alpha$-M carbamate derivatives AMG-1-AMG-16.

In Vitro Experiments. Sixteen derivatives of AMG were evaluated for $\mathrm{AChE}$ inhibition by an in vitro assay based on a microplate. The $\mathrm{IC}_{50}$ values for $\mathrm{AChE}$ inhibition are summarized in Table 1. A majority of the derivatives showed potent capacity to inhibit $\mathrm{AChE}$ activity, with $\mathrm{IC}_{50}$ values lying in the micromolar range, which demonstrates an important role of the $\alpha-\mathrm{M}$ moiety in the AChE inhibition of the developed $\alpha-\mathrm{M}$ carbamate group. The neuroprotective activity of target compounds was evaluated on the neuronal-like PC12 cells damaged by $\mathrm{H}_{2} \mathrm{O}_{2}$. The results expressed as $\mathrm{EC}_{50}$ are shown in Table 1 , and most of the $\alpha$-M derivatives showed better protective effects than the positive control drug edaravone $\left(\mathrm{EC}_{50}=69.98 \pm 5.73 \mu \mathrm{M}\right)$ on injured PC12 cells. The $\mathrm{EC}_{50}$ of $\alpha-\mathrm{M}$ was tested to be more than $100 \mu \mathrm{M}$. Among the AMG derivatives, AMG-1 exhibited the most potent neuroprotective activity, with $\mathrm{EC}_{50}$ values of $1.61 \pm 0.35 \mu \mathrm{M}$. The cytotoxicity was compared between $\alpha-\mathrm{M}$ and derivatives in PC12 cells. The results showed that the inhibition ratio of cell proliferation decreased from 73.1 to $45.3 \%$ after the cyclization of $\alpha$-M to AMG (Table 2). Notably, AMG-1, which was then selected for the in vivo studies on the rat model of $\mathrm{AD}$, has an inhibition ratio of $7.2 \%$.

Table 2. Cytotoxic Effects of $\alpha-\mathrm{M}$ and Derivatives in PC12 Cells

\begin{tabular}{cccc}
$\begin{array}{c}\text { compounds } \\
\mu \mathrm{M})\end{array}$ & $\begin{array}{c}\text { inhibition ratio } \\
(\%)\end{array}$ & $\begin{array}{c}\text { compounds } \\
\mu \mathrm{M})\end{array}$ & $\begin{array}{c}\text { inhibition ratio } \\
(\%)\end{array}$ \\
edaravone & 0 & AMG-8 & 0 \\
$\alpha$-M & 73.1 & AMG-9 & 0 \\
AMG & 45.3 & AMG-10 & 0 \\
AMG-1 & 7.2 & AMG-11 & 0 \\
AMG-2 & 6.7 & AMG-12 & 0 \\
AMG-3 & 5.9 & AMG-13 & 3.1 \\
AMG-4 & 0 & AMG-14 & 5.3 \\
AMG-5 & 7.8 & AMG-15 & 5.2 \\
AMG-6 & 7.4 & AMG-16 & 0 \\
AMG-7 & 0 & & \\
\hline
\end{tabular}

In Vivo Experiments. Acute Toxicity. During the acute oral toxicity experiment period, the mice were found to have messy furs and loose gray stool around the anus. Except for the $1310 \mathrm{mg} / \mathrm{kg}$ group, death could be found in other groups (Table 3). Particularly, the mice in the highest dosed group (4000 mg/kg) were found dead within 16-48 $\mathrm{h}$ after

Table 3. Results of the Acute Oral Toxicity Test of AMG-1 in Mice

$\begin{array}{lcccc}\text { group } & \text { number of rats } & \text { dosage }(\mathrm{mg} / \mathrm{kg}) & \text { deaths } & \text { death rate }(\%) \\ \text { control } & 10 & & 0 & 0 \\ 1 & 10 & 4000 & 9 & 90 \\ 2 & 10 & 3200 & 7 & 70 \\ 3 & 10 & 2560 & 6 & 60 \\ 4 & 10 & 2048 & 4 & 40 \\ 5 & 10 & 1638 & 1 & 10 \\ 6 & 10 & 1310 & 0 & 0\end{array}$

administration. For the 14 day observation, most mice had a recovery. $\mathrm{LD}_{50}$ values and their $95 \%$ confidence intervals of AMG-1 in mice were calculated according to the improved Bliss method. The results indicated that the $\mathrm{LD}_{50}$ values of AMG-1 in mice were $2.47 \mathrm{~g} / \mathrm{kg}$ and the $95 \%$ confidence intervals were between 2.13 and $2.89 \mathrm{~g} / \mathrm{kg}$. Results showed that AMG-1 had no obvious toxicity at the level of $20 \mathrm{mg} / \mathrm{kg}$ or less as the dose for administration in the following studies.

Animal Behavior Tests in the Open Field and Morris Water Maze. The one-way ANOVA analysis of locomotor activity and distance traveled in the open field showed the treatment effects of AMG-1 on $\mathrm{AD}$ rats. The total distance moved by the $\mathrm{A} \beta$ model group was the shortest among the six groups (Figure $1 \mathrm{~A}$ ), and the $\mathrm{A} \beta$ model group spent the least time in the central zone (Figure $1 \mathrm{~B}$ ), indicating the low ability of space exploration in the $\mathrm{A} \beta$ model group on average. However, both the AMG-1 $(20 \mathrm{mg} / \mathrm{kg})$-treated group and the donepezil group showed a significant increase compared to the A $\beta$ model group $(p<0.05, p<0.01)$ in the total distance moved $(28.55 \pm 6.87,31.37 \pm 7.14$, vs $17.34 \pm 3.88$, respectively). AMG-1-treated groups showed a significant $(p<$ $0.05-0.01)$ and dose-dependent increase in the time spent in the central zone compared to the $\mathrm{A} \beta$ model group $(p<0.01)$.

To examine whether the ability of spatial learning and memory was significantly improved by administering AMG-1 in $\mathrm{AD}$ rats, we adopted a commonly utilized Morris water maze test for evaluation. The results exhibited that in the training trials on the first day, all rats explored the objects equally (Figure $1 \mathrm{~A}, p>0.05$ ). During the retention phase, the escape latency (Figure 1C) and the total distance traveled (Figure 1D) of the rats in the $\mathrm{A} \beta$-induced model group were significantly increased compared to the rats in the sham control group $(p<0.01)$, while AMG-1-treated rats showed significant improvements compared to the model rats $(p<$ 0.05 ). In the probe trial (Figure $1 \mathrm{E}$ ), the platform was removed. AMG-1 treatment not only promoted learning during the training trials but also improved memory retention during the probe trials. Rats in AMG-1 treatment groups spent significantly less time to reach the place of the removed platform and spent significantly more time in the target quadrant, compared to the model rats $(p<0.05)$. Thus, these results demonstrate that AMG-1 treatment can improve the memory loss in $\mathrm{A} \beta$-induced rats.

Neuroprotective Effects of AMG-1 Revealed by Brain Tissue Staining. Hematoxylin and Eosin (HE) staining was performed to detect the pyramidal cells of the hippocampus CA3 region and the neurohistopathological changes in the brain sections in rats in different groups under a light microscope $(200 \times)$. The representative morphologic pictures of neuronal cells of the rats from HE staining are illustrated in Figure 2. Figure 2A shows no remarkable neuronal abnormalities in the hippocampus CA3 region of rats in the sham control group. The pyramidal cells of the CA3 region are arranged neatly and tightly, and no cell loss can be found. Cells are round and intact with nuclei stained clearly in dark blue (red arrows in Figure 2A). However, obvious hippocampal histopathological damage is observed in the model group. The pyramidal layered structure is disintegrated, and neuronal loss can be found in the CA3 region. Pyramidal neurons with pyknotic nuclei and a shrunken or irregular shape can also be observed (Figure 2B). These abnormalities were attenuated by AMG-1 treatment. The pyramidal cells in the AMG-1 (5, 10, 

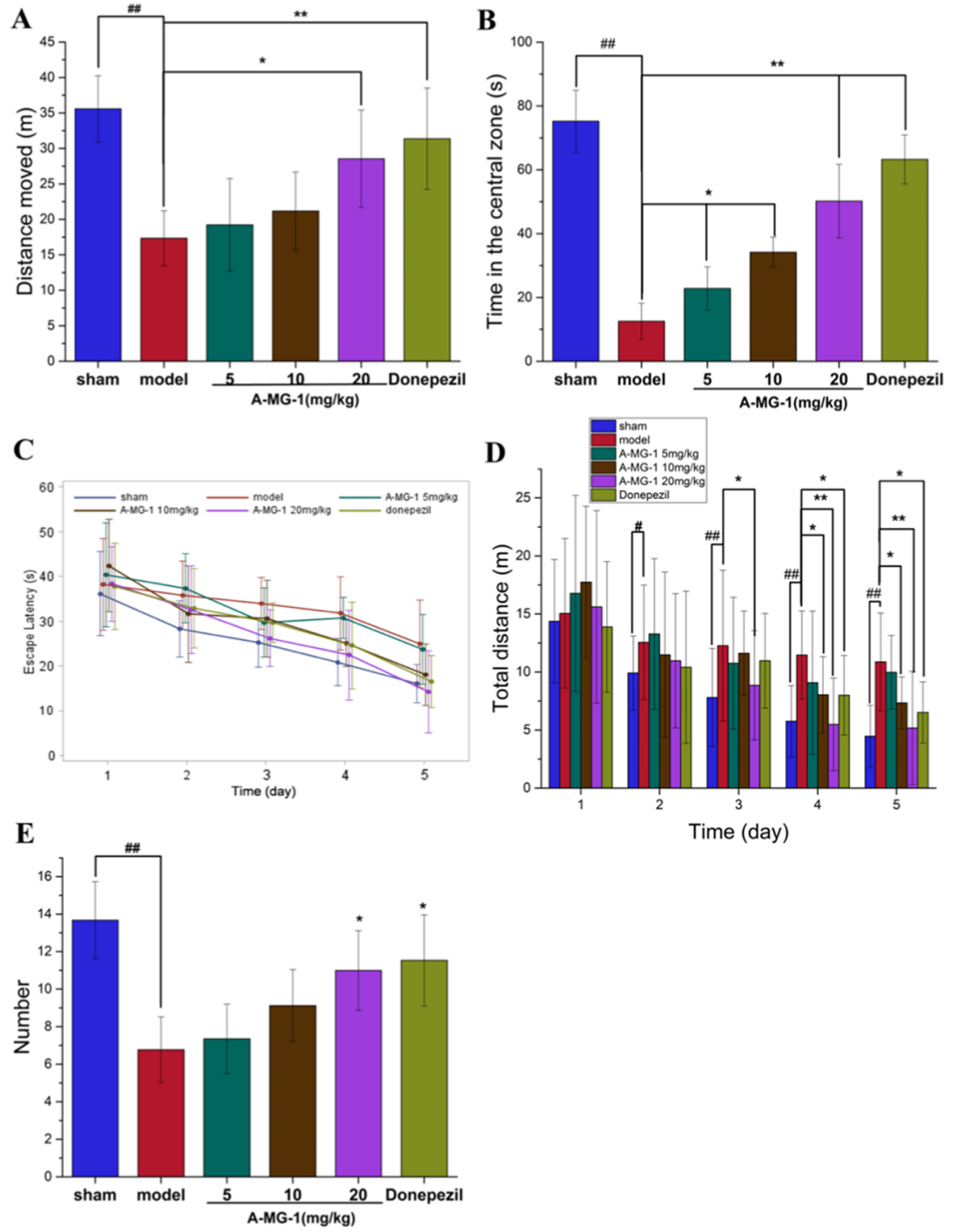

Figure 1. Effect of AMG-1 administration on behaviors related to locomotor activity and the improvement of spatial cognition in $\mathrm{AD}$ rats. (A) Total distance moved and (B) time spent in the central zone in the OFT. (C) Effect of AMG-1 on escape latency, (D) total distance moved, and (E) number of crossings in the MWM. (Values are expressed as mean \pm SEM and were analyzed using the $t$-test. \#P $<0.05$, \#\#P $<0.01$ compared with the sham group and $* P<0.05 * * P<0.01$ compared with the $\mathrm{A} \beta$ model group in each figure).

and $20 \mathrm{mg} / \mathrm{kg}$ ) groups have better cell morphology and density than those in the model group (Figure $2 \mathrm{D}-\mathrm{F}$ ).

In the hippocampal $\mathrm{CA} 1$ and $\mathrm{CA} 3$ areas, representative Nissl-stained neurons can be observed in Figure 3. Intact cells can be found in sham-operated animals as well as all unaffected regions following $\mathrm{AD}$. The results from the Nissl staining showed that in the hippocampal CA1 area of $\mathrm{AD}$ rats, the cells were sparsely distributed and the number of cells with eumorphism was significantly reduced. Based on the results, A $\beta$ significantly increased necrotic death in the hippocampal CA1 region of the rats in the $A \beta$ model group, compared with the rats in the sham group (Figure $3 \mathrm{~A}, \mathrm{~B}$ ). However, with the AMG-1 treatment, neuronal damage was significantly attenuated in rats in 10 and $20 \mathrm{mg} / \mathrm{kg}$ groups, which suggested that AMG-1 can significantly prevent the neuronal loss in $\mathrm{A} \beta$ induced $\mathrm{AD}$ rats (Figure $3 \mathrm{E}-\mathrm{G}$ ).

To evaluate the effects of AMG-1 on the $\mathrm{AD}$ rat model, neurofibrillary tangle pathology was observed by modified Bielschowsky silver staining. The notable dark neurofibrillary tangles (red arrows in Figure 4) that characterize the neuronal damage in the hippocampus can be found for rats in the $\mathrm{A} \beta_{25-35}$-treated group (Figure $4 \mathrm{~B}-\mathrm{F}$ ). The damaged neurons can rarely be found in the hippocampus for rats in the sham group (Figure 4A). A large amount of dark staining of neurons and senile plaques can be frequently observed in the hippocampus for rats in the $\mathrm{AD}$ model group (Figure 4B). Meanwhile, the number of senile plaques for rats in the AMG1 treatment $(10,20 \mathrm{mg} / \mathrm{kg}$ ) groups was less (Figure 4E,F). Our data demonstrate that amyloid exposure can induce senile plaque deposition. Furthermore, the results suggest that AMG1 can reduce the senile plaques and repair the neuron injury for the $\mathrm{AD}$ model rats.

AMG-1 Treatment Decreases $A \beta_{1-42}$ in the Hippocampus of the AD Rat Brain. Quantification of immunohistochemical staining for $\mathrm{A} \beta_{1-42}$ showed that there are significantly more positive-stained neurons for rats in the model group $(p<0.01)$ than in the sham group (Figure 5A,B). Compared with the model group, the AMG-1 treatment groups $(10,20 \mathrm{mg} / \mathrm{kg}$ ) 


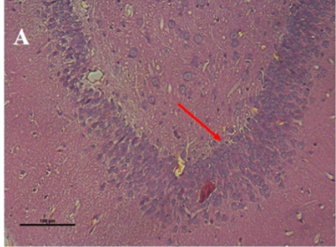

$\operatorname{Sham}(200 x)$

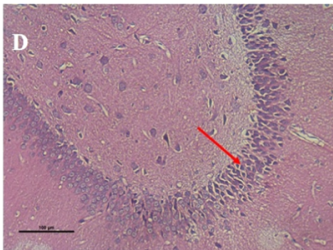

A-MG-1 5mg/kg (200x)

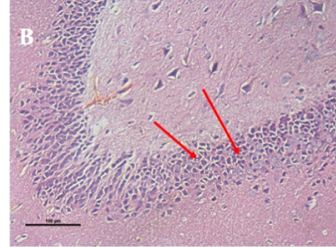

Model (200x)

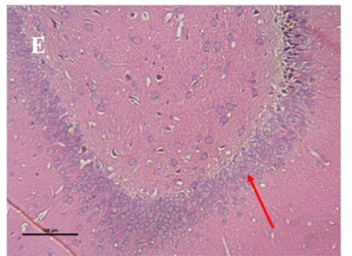

A-MG-1 10mg/kg (200x)

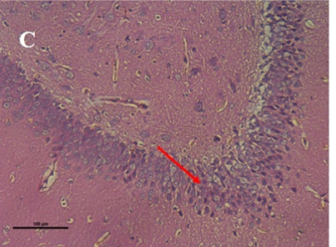

Donepezil (200x)

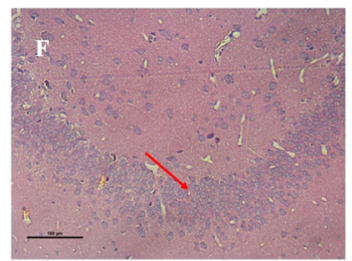

A-MG-1 20mg/kg (200x)

Figure 2. HE staining of the neuronal cells of the hippocampus CA3 region. Hematoxylin and eosin staining of the hippocampus CA3 region. The red arrows indicate the histologic changes $(\times 200)$. (A) Sham group, (B) A $\beta$ model group, and (C) donepezil group. (D-F) AMG-1 (5, 10, and 20 $\mathrm{mg} / \mathrm{kg})+$ the model group, respectively.

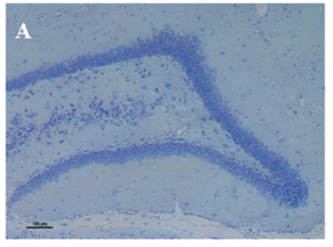

$\operatorname{Sham}(\mathbf{1 0 0 x})$

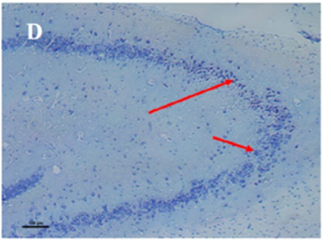

A-MG-1 5mg/kg (100x)

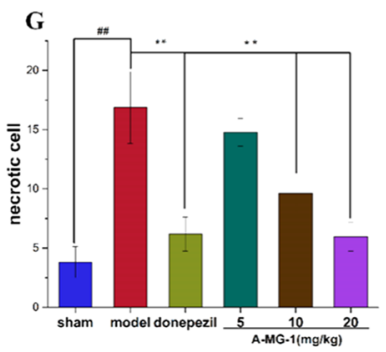

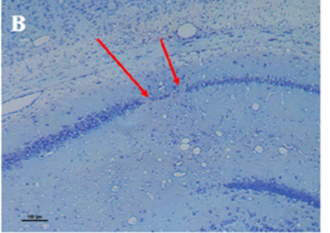

Model (100x)

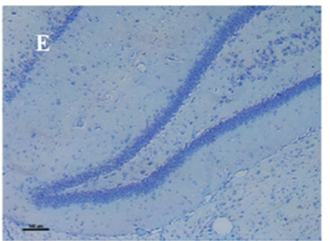

A-MG-1 10mg/kg (100x)

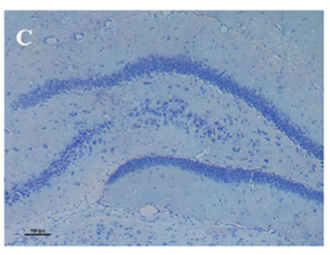

Donepezil (100x)

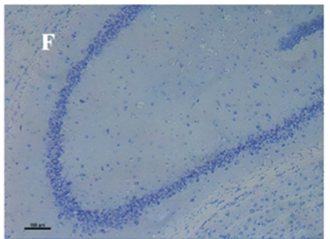

A-MG-1 20mg/kg (100x)

Figure 3. Nissl staining of the hippocampal CA1 region after induction of A $\beta$. Damaged cells $(n=5$ rats per group, three sections per rat) were sparsely arranged, and their shapes were fuzzy (the red arrows indicate the necrotic cells). (A) Sham group, (B) A $\beta$ model group, (C) donepezil group, and (D-F) AMG-1 (5, 10, and $20 \mathrm{mg} / \mathrm{kg})+$ model group, respectively. The results are shown as mean \pm SED. (G) Quantitative analysis of the necrotic cell count.

showed a significantly reduced expression of $\mathrm{A} \beta_{1-42}(p<0.05)$ (Figure 5E-G). Red arrows show areas of $\mathrm{A} \beta_{1-42}$-positive amyloid plaques.

Chemogenomics Knowledgebase Network Analysis. In the observation of experimental evidence, AMG-1 remarkably reversed behavioral deficits and significantly improved cognitive functions in $\mathrm{AD}$ model rats. The results suggest that the neuroprotective effects of AMG-1 are realized through scavenging $\beta$-amyloid in the hippocampus. To (1) better understand the complex interaction of the compound and the corresponding targets and (2) establish a comprehensive understanding of the therapeutic mechanisms, the chemogenomics knowledgebase was adapted for network analysis.

Chemogenomics databases for Alzheimer's disease, drug abuse research, and cardiovascular disease, as well as two chemogenomics tools, TragetHunter and HTDocking, were combined for retrieving the information for protein targets as detailed in the Materials and Methods section. The compoundtarget network was first constructed (Figure 6). In total, 55 nodes of protein targets were connected with $\alpha$-mangostin and AMG through 68 edges (Table 4). A total of 33 protein targets were predicted to have an association with $\alpha$-mangostin, while 35 protein targets were predicted to interact with AMG-1. 


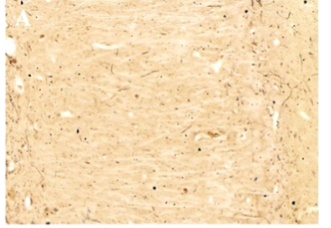

Sham(400x)

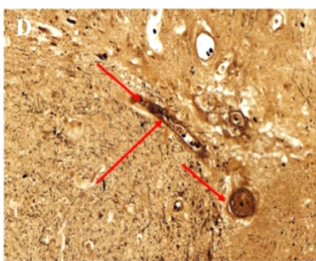

A-MG-1 5mg/kg (400x)

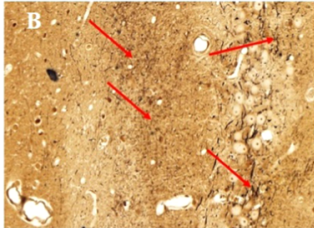

Model (400x)

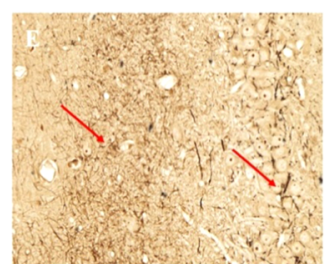

A-MG-1 10mg/kg (400x)

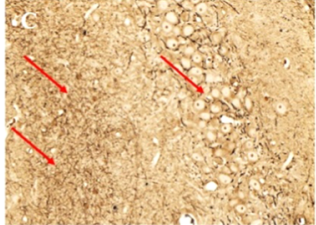

Donepezil (400x)

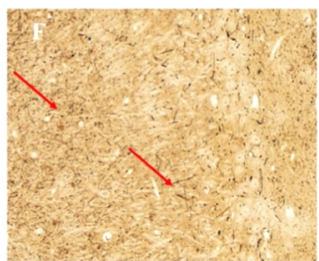

A-MG-1 20mg/kg (400x)

Figure 4. Silver staining. Administration of AMG-1 to animals for 30 days (D-F) in comparison to (C) donepezil, (B) model, and (A) sham rats.

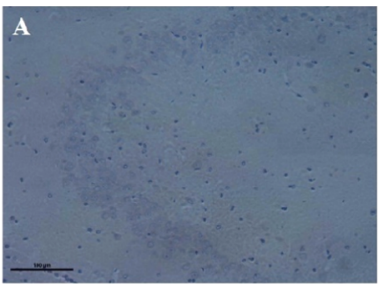

$\operatorname{Sham}(200 x)$

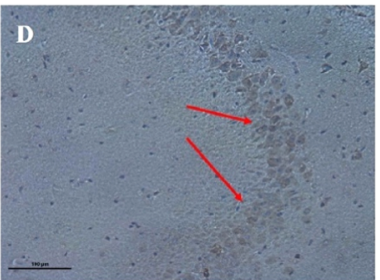

A-MG-1 5mg/kg (200x)

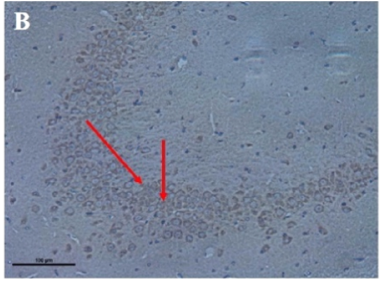

Model (200x)

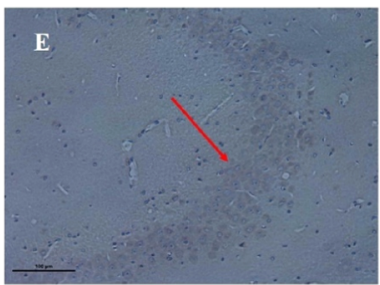

A-MG-1 10mg/kg (200x)

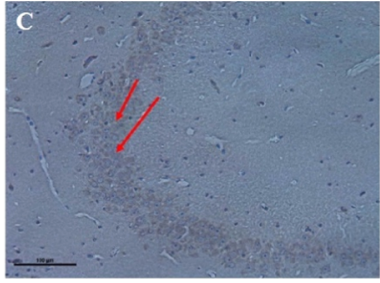

Donepezil (200x)

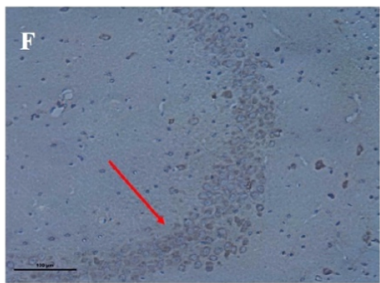

A-MG-1 20mg/kg (200x)

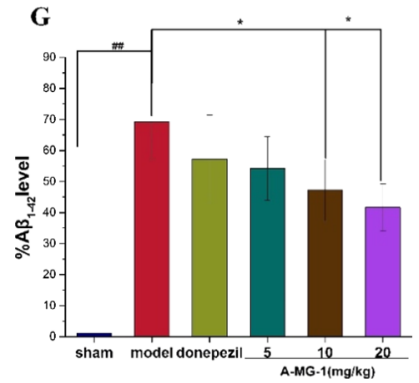

Figure 5. Effect of AMG-1 on A $\beta 1-42$ expression in the hippocampal CA1 region. (A) Sham rat group, (B) A $\beta$ model group, (C) donepezil treatment group, and (D-F) AMG-1 treatment rat groups (5, 10, $20 \mathrm{mg} / \mathrm{kg} / \mathrm{day})(n=4$, four sections per rat). (G) Quantification of the immunohistochemistry of $\mathrm{A} \beta$ plaque numbers in the hippocampus $(n=4$, four sections per rat).

Thirteen nodes were shared between the two compounds. The annulation and the substitution of two hydroxyl groups changed the size and the physical-chemical properties of $\alpha$ mangostin. As a result, distinctive targets can be observed between these two compounds. The reported targets for $\alpha$ mangostin were recurred and marked in green. The effect of AMG-1 on preventing Tau hyperphosphorylation was proposed through the experiments and marked in yellow.

The analysis of signaling pathways (Figure 7) was followed to connect the protein targets with both physiological and pathological processes. Targets were identified to be involved in a total of 37 nodes of pathways through 94 edges. The complexity of the network reflects the polypharmacology feature of $\alpha$-mangostin and its derivative, AMG-1, which is consistent with the broad therapeutic spectrum of these compounds. Pathways connected with more than three targets were placed in the center and colored in orange for emphasis. Among the highly shared pathways, signaling in cholinergic neurons, cholesterol and sphingolipid transport and biosynthesis, and tau pathology can have a direct or indirect association with $\mathrm{AD}$. Oxidative phosphorylation, neuroprotective action of lithium, etc. can also have influences on the pathology of $\mathrm{AD}$. The effect of AMG-1 on treating diseases can be in a one-molecule, multiple-targets manner. 


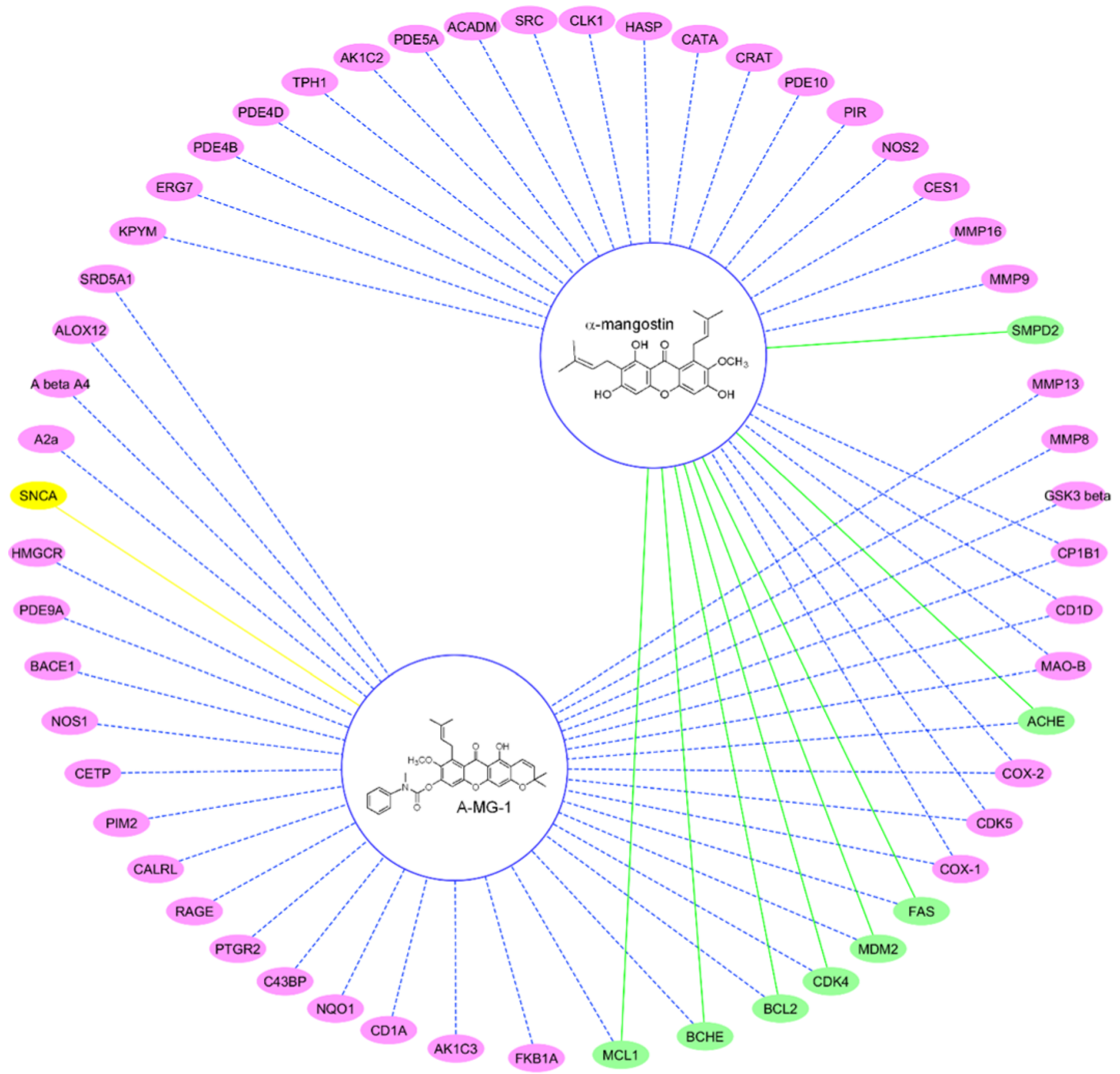

Figure 6. Chemogenomics-based target mapping for $\alpha$-mangostin and AMG-1. Pink nodes represent the purely predicted targets. Yellow nodes represent the experimentally validated targets. Green nodes represent the known targets. Known or experimentally validated targets are connected with the corresponding target through solid edges. Predicted targets are connected through dashed edges.

The target-pathway network bridged the gap between the targets and the specific diseases. The target-disease network (Figure 8) was constructed afterward. A total of 25 nodes of diseases were connected with targets through 125 edges. Most diseases can be categorized into four groups: neurological, cancer-related, cardiovascular, and inflammatory diseases. The reported effects of $\alpha$-mangostin on treating cancers, benefiting cardiovascular disorders, and improving cognitive functions can be recurred or verified in the target-disease network. Limited reports can be found to associate $\alpha$-mangostin and neurological disorders, except $\mathrm{AD}$. However, the potential of $\alpha$-mangostin and AMG-1 for treating other neurological disorders, including depression, Parkinson's disease, and Huntington's disease, can be investigated. One explanation that the identified diseases are mainly neurological and cardiovascular is that the chemogenomics knowledgebase we used focuses on $\mathrm{AD}$, drug abuse, and the cardiovascular system. It is a shortcoming that using focused knowledgebases can have a limited target coverage. However, on the other hand, using focused knowledgebases according to reported compound activities can better develop a systematic understanding of the specific areas, especially for the $\mathrm{AD}$ research in this case.

For the node of $\mathrm{AD}, 18$ edges were connected to a variety of protein targets. An $\mathrm{AD}$-specific target-disease network of $\alpha$ mangostin and AMG-1 was then constructed (Figure 9). Seven nodes of targets were connected with $\alpha$-mangostin, and 15 nodes of targets were connected with AMG-1, while four targets were shared between these two compounds. Seventeen nodes of targets (except TPH1) were categorized into five groups: $\beta$-amyloid (A $\beta$ ) deposit, deficits of acetylcholine, tau hyperphosphorylation, oxidative stress, and lipid metabolism, 
Table 4. Protein Annotation for the Predicted Targets ${ }^{a}$

\begin{tabular}{|c|c|c|c|}
\hline protein & $\begin{array}{l}\text { docking } \\
\text { score }\end{array}$ & gene name & compound \\
\hline cytochrome P450 1B1 (CP1B1_HUMAN) & 11.7 & CP1B1 & $\alpha$-mangostin \\
\hline pyruvate kinase isozymes M1/M2 (KPYM_HUMAN) & 11.6 & KPYM & $\alpha$-mangostin \\
\hline amine oxidase [flavin-containing] B, Monoamine oxidase type B, MAO-B & 11.0 & MAO-B & $\alpha$-mangostin \\
\hline lanosterol synthase (ERG7_HUMAN) & 10.9 & ERG7 & $\alpha$-mangostin \\
\hline acetylcholinesterase, $\mathrm{AChE}$ & 10.9 & ACHE & $\alpha$-mangostin \\
\hline cAMP-specific $3^{\prime}, 5^{\prime}$-cyclic phosphodiesterase 4B (PDE4B_HUMAN) & 10.8 & PDE4B & $\alpha$-mangostin \\
\hline cAMP-specific $3^{\prime}, 5^{\prime}$-cyclic phosphodiesterase 4D (PDE4D_HUMAN) & 10.7 & PDE4D & $\alpha$-mangostin \\
\hline prostaglandin G/H synthase 2, Cyclooxygenase-2, COX-2 & 10.7 & COX-2 & $\alpha$-mangostin \\
\hline tryptophan 5-hydroxylase 1 (TPH1_HUMAN) & 10.6 & TPH1 & $\alpha$-mangostin \\
\hline aldo-keto reductase family 1 member C2 (AK1C2_HUMAN) & 10.5 & $\mathrm{AK} 1 \mathrm{C} 2$ & $\alpha$-mangostin \\
\hline cGMP-specific $3^{\prime}, 5^{\prime}$-cyclic phosphodiesterase (PDE5A_HUMAN) & 10.5 & PDE5A & $\alpha$-mangostin \\
\hline medium-chain specific acyl-CoA dehydrogenase, mitochondrial (ACADM_HUMAN) & 10.3 & ACADM & $\alpha$-mangostin \\
\hline proto-oncogene tyrosine-protein kinase Src (SRC_HUMAN) & 10.3 & SRC & $\alpha$-mangostin \\
\hline nitric oxide synthase, inducible; NOS type II; NOS2 & 10.3 & NOS2 & $\alpha$-mangostin \\
\hline cyclooxygenase & 10.3 & $\mathrm{COX}-1$ & $\alpha$-mangostin \\
\hline T-cell surface glycoprotein CD1d (CD1D_HUMAN) & 10.2 & CD1D & $\alpha$-mangostin \\
\hline dual specificity protein kinase CLK1 (CLK1_HUMAN) & 10.2 & CLK1 & $\alpha$-mangostin \\
\hline serine/threonine-protein kinase haspin (HASP_HUMAN) & 10.2 & HASP & $\alpha$-mangostin \\
\hline catalase (CATA_HUMAN) & 10.1 & CATA & $\alpha$-mangostin \\
\hline catalase (CATA_HUMAN) & 10.1 & CATA & $\alpha$-mangostin \\
\hline carnitine $\mathrm{O}$-acetyltransferase (CACP_HUMAN) & 10.1 & CRAT & $\alpha$-mangostin \\
\hline cAMP and cAMP-inhibited cGMP $3^{\prime}, 5^{\prime}$-cyclic phosphodiesterase 10A (PDE10_HUMAN) & 10.1 & PDE10 & $\alpha$-mangostin \\
\hline pirin (PIR_HUMAN) & 10.1 & PIR & $\alpha$-mangostin \\
\hline liver carboxylesterase 1; Brain carboxylesterase hBr1; CES1 & 9.9 & CES1 & $\alpha$-mangostin \\
\hline cyclooxygenase & 9.7 & $\mathrm{COX}-2$ & $\alpha$-mangostin \\
\hline cyclin-dependent kinase 5; Cell division protein kinase 5; CDK5 & 9.6 & CDK5 & $\alpha$-mangostin \\
\hline sphingomyelin phosphodiesterase 2; SMPD2 & 9.4 & SMPD2 & $\alpha$-mangostin \\
\hline matrix metalloproteinase-16 (MMP16_HUMAN) & 9.3 & MMP16 & $\alpha$-mangostin \\
\hline matrix metalloproteinase-9 (MMP9_HUMAN) & 9.3 & MMP9 & $\alpha$-mangostin \\
\hline E3 ubiquitin-protein ligase Mdm2 (MDM2_HUMAN) & 7.9 & MDM2 & $\alpha$-mangostin \\
\hline apoptosis regulator Bcl-2 (BCL2_HUMAN) & 7.6 & BCL2 & $\alpha$-mangostin \\
\hline G1/S-specific cyclin-D3@Cell division protein kinase 4(CCND3_HUMAN/CDK4_HUMAN) & 7.0 & $\mathrm{CDK} 4$ & $\alpha$-mangostin \\
\hline fatty acid synthase (FAS_HUMAN) & 6.7 & FAS & $\alpha$-mangostin \\
\hline induced myeloid leukemia cell differentiation protein Mcl-1 (MCL1_HUMAN) & 5.7 & MCL1 & $\alpha$-mangostin \\
\hline acetylcholinesterase, $\mathrm{AChE}$ & 12.3 & ACHE & AMG-1 \\
\hline cholinesterase, Butyrylcholine esterase, BCHE & 12.3 & BCHE & AMG-1 \\
\hline nitric oxide synthase, brain; Neuronal NOS; NOS type I; NOS1 & 12.2 & NOS1 & AMG-1 \\
\hline peptidyl-prolyl cis-trans isomerase FKBP1A (FKB1A_HUMAN) & 12.1 & FKB1A & AMG-1 \\
\hline aldo-keto reductase family 1 member C3 (AK1C3_HUMAN) & 12.0 & $\mathrm{AK} 1 \mathrm{C} 3$ & AMG-1 \\
\hline T-cell surface glycoprotein CD1d (CD1D_HUMAN) & 11.9 & CD1D & AMG-1 \\
\hline T-cell surface glycoprotein CD1a (CD1A_HUMAN) & 11.8 & CD1A & AMG-1 \\
\hline NAD $(\mathrm{P}) \mathrm{H}$ dehydrogenase [quinone] 1 (NQO1_HUMAN) & 11.8 & NQO1 & AMG-1 \\
\hline collagen type IV $\alpha$-3-binding protein (C43BP_HUMAN) & 11.7 & $\mathrm{C} 43 \mathrm{BP}$ & AMG-1 \\
\hline prostaglandin reductase 2 (PTGR2_HUMAN) & 11.7 & PTGR2 & AMG-1 \\
\hline cytochrome P450 1B1 (CP1B1_HUMAN) & 11.5 & CP1B1 & AMG-1 \\
\hline advanced glycosylation end product-specific receptor (RAGE_HUMAN) & 11.4 & RAGE & AMG-1 \\
\hline $\begin{array}{l}\text { calcitonin gene-related peptide type } 1 \text { receptor, Receptor activity-modifying protein 1(CALRL_HUMAN/ } \\
\text { RAMP1_HUMAN) }\end{array}$ & 11.3 & CALRL & AMG-1 \\
\hline serine/threonine-protein kinase Pim-2 (PIM2_HUMAN) & 11.2 & PIM2 & AMG-1 \\
\hline cholesteryl ester transfer protein (CETP_HUMAN) & 11.2 & CETP & AMG-1 \\
\hline cyclin-dependent kinase 5; Cell division protein kinase 5; CDK5 & 11.1 & CDK5 & AMG-1 \\
\hline glycogen synthase kinase- $3 \beta$, GSK3 $\beta$, GSK3B & 10.6 & GSK3 $\beta$ & AMG-1 \\
\hline amine oxidase [flavin-containing] B, Monoamine oxidase type B, MAO-B & 10.6 & MAO-B & AMG-1 \\
\hline$\beta$-secretase 1 , Aspartyl protease 2, BACE1 & 10.5 & BACE1 & AMG-1 \\
\hline high-affinity cGMP-specific $3^{\prime}, 5^{\prime}$-cyclic phosphodiesterase 9A, PDE9A & 10.3 & PDE9A & AMG-1 \\
\hline 3-hydroxy-3-methylglutaryl-coenzyme A reductase; HMG-CoA reductase; HMGCR & 10.2 & HMGCR & AMG-1 \\
\hline$\alpha$-synuclein (Tau) & 10.2 & SNCA & AMG-1 \\
\hline steroid $5 \alpha$-reductase 1 & 10.1 & SRD5A1 & AMG-1 \\
\hline prostaglandin G/H synthase 2, Cyclooxygenase-2, COX-2 & 10.0 & COX-2 & AMG-1 \\
\hline adenosine $\mathrm{A} 2 \mathrm{a}$ receptor & 10.0 & $\mathrm{~A} 2 \mathrm{a}$ & AMG-1 \\
\hline
\end{tabular}


Table 4. continued

\begin{tabular}{|c|c|c|c|}
\hline protein & $\begin{array}{c}\text { docking } \\
\text { score }\end{array}$ & gene name & compound \\
\hline cyclooxygenase & 9.9 & COX-1 & AMG-1 \\
\hline amyloid $\beta$ A4 protein & 9.7 & A $\beta$ A 4 & AMG-1 \\
\hline collagenase 3 (MMP13_HUMAN) & 9.5 & MMP13 & AMG-1 \\
\hline neutrophil collagenase (MMP8_HUMAN) & 9.3 & MMP8 & AMG-1 \\
\hline E3 ubiquitin-protein ligase Mdm2 (MDM2_HUMAN) & 8.9 & MDM2 & AMG-1 \\
\hline G1/S-specific cyclin-D3@Cell division protein kinase 4 (CCND3_HUMAN/CDK4_HUMAN) & 8.3 & CDK4 & AMG-1 \\
\hline apoptosis regulator Bcl-2 (BCL2_HUMAN) & 8.1 & BCL2 & AMG-1 \\
\hline fatty acid synthase (FAS_HUMAN) & 8.0 & FAS & AMG-1 \\
\hline arachidonate 12-lipoxygenase & 7.8 & ALOX12 & AMG-1 \\
\hline induced myeloid leukemia cell differentiation protein Mcl-1 (MCL1_HUMAN) & 5.7 & MCL1 & AMG-1 \\
\hline
\end{tabular}

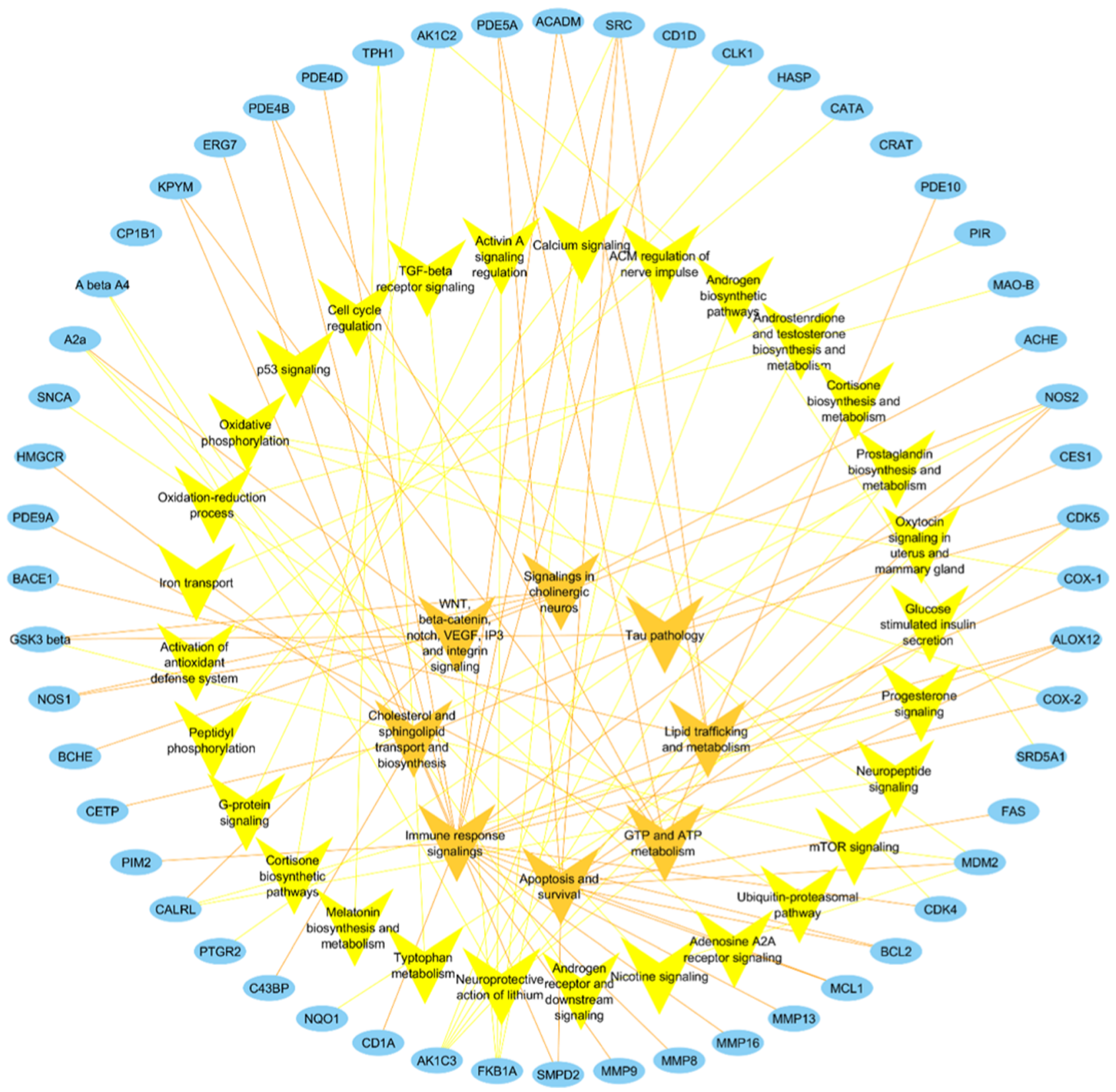

Figure 7. Target-pathway network. Blue nodes represent the targets for $\alpha$-mangostin and AMG-1 identified through the target mapping. Yellow and orange nodes represent signaling pathways or processes. In particular, orange nodes are shared by three or more targets and placed in the center for emphasis. 


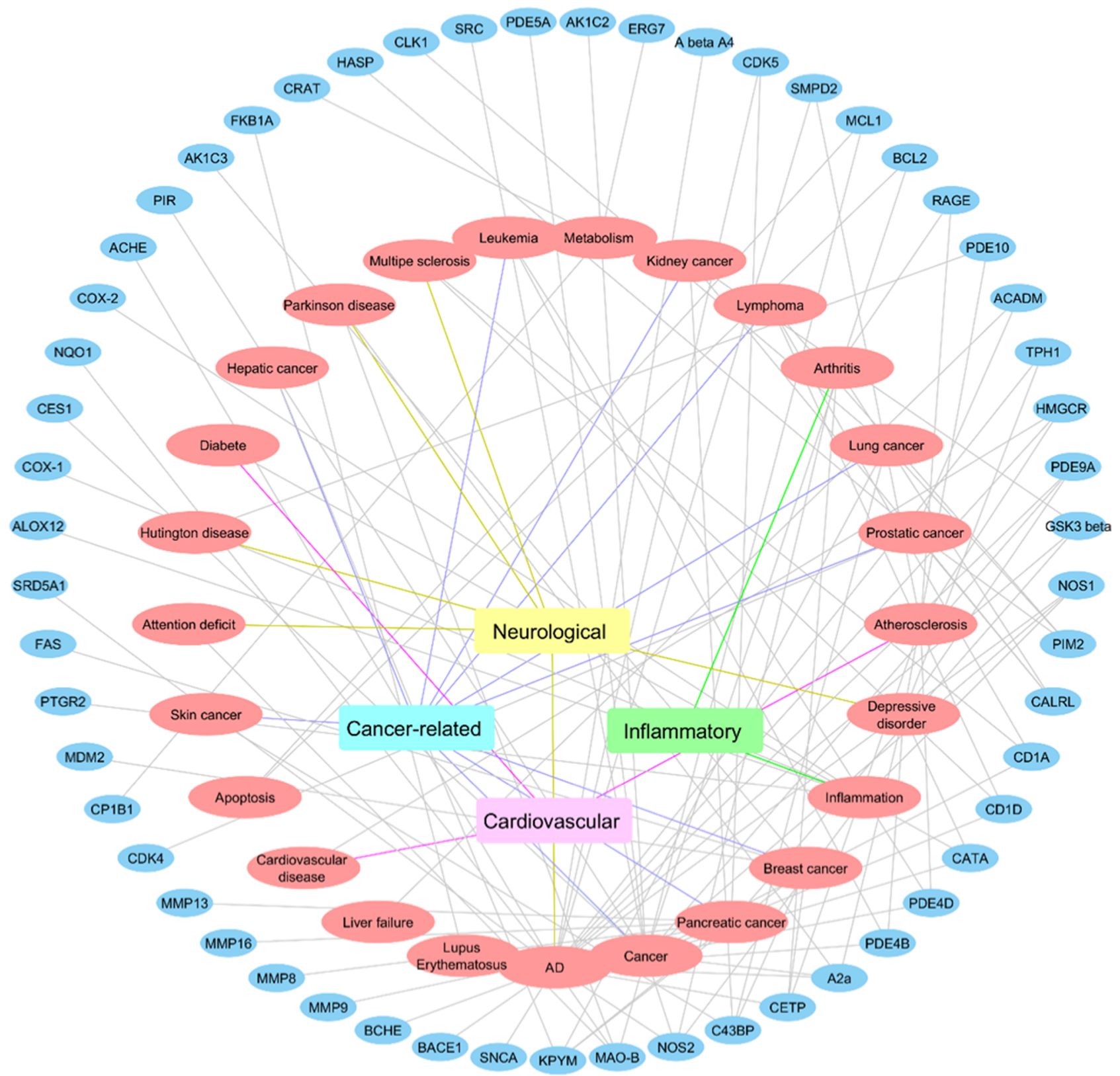

Figure 8. Target-disease network. Blue nodes represent the targets for $\alpha$-mangostin and AMG-1 identified through the target mapping. Salmon nodes represent different diseases. Diseases are categorized into four categories, neurological, cancer-related, cardiovascular, and inflammatory. Diseases are connected with categories with edges in the corresponding color.

according to their association in pathology hypothesis regarding $\mathrm{AD}$. Among these five groups, lipid metabolism may attract relatively less attention. Besides having been reported to be associated with $\mathrm{A} \beta$ deposit and tau hyperphosphorylation, lipid metabolism can also have a direct or unclear effect on $\mathrm{AD}$ pathology, including (1) biosynthesis of neuroprotective allopregnalolone, (2) regulation of cholesteryl ester transformation, and (3) interference in the metabolism of sphingomyelin. The distinctions in predicted targets for $\alpha$ mangostin and AMG-1 reflected the alteration in physicalchemical properties caused by the annulation and the substitution on two hydroxyl groups of $\alpha$-mangostin. The experimentally observed inhibition of tau hyperphosphorylation from straining can be caused directly by interacting SNCA and indirectly by interfering GSK $3 \beta$. In addition, the prevention of $\mathrm{A} \beta$ deposit can be the result of the interaction of BACE1, CDK5, and HMGCR. Also, AMG-1 can inherit the ability of $\alpha$-mangostin to inhibit cholinesterases, which further benefits the $\mathrm{AD}$ treatment. Further investigation can be conducted toward NQO1 and CETP. In response to the increased oxidatives, NADPH quinone oxidoreductase (NQO1) can be activated. The reduced HDL level can be observed in $\mathrm{AD}$, which can be a result of regulating the cholesteryl ester transfer protein (CETP). The regulation in lipid metabolism and oxidative stress can contribute to the therapeutic potential of AMG-1. The finding supports the hypothesis that AMG-1 demonstrates its therapeutic effects in a one-molecule, multiple-targets manner.

In Silico Property Prediction. The experimental results clearly show the neuroprotective effects of AMG-1. Given that the targeting site for treating $\mathrm{AD}$ is in the central nervous system, it is critical to evaluate the ability of a compound to 


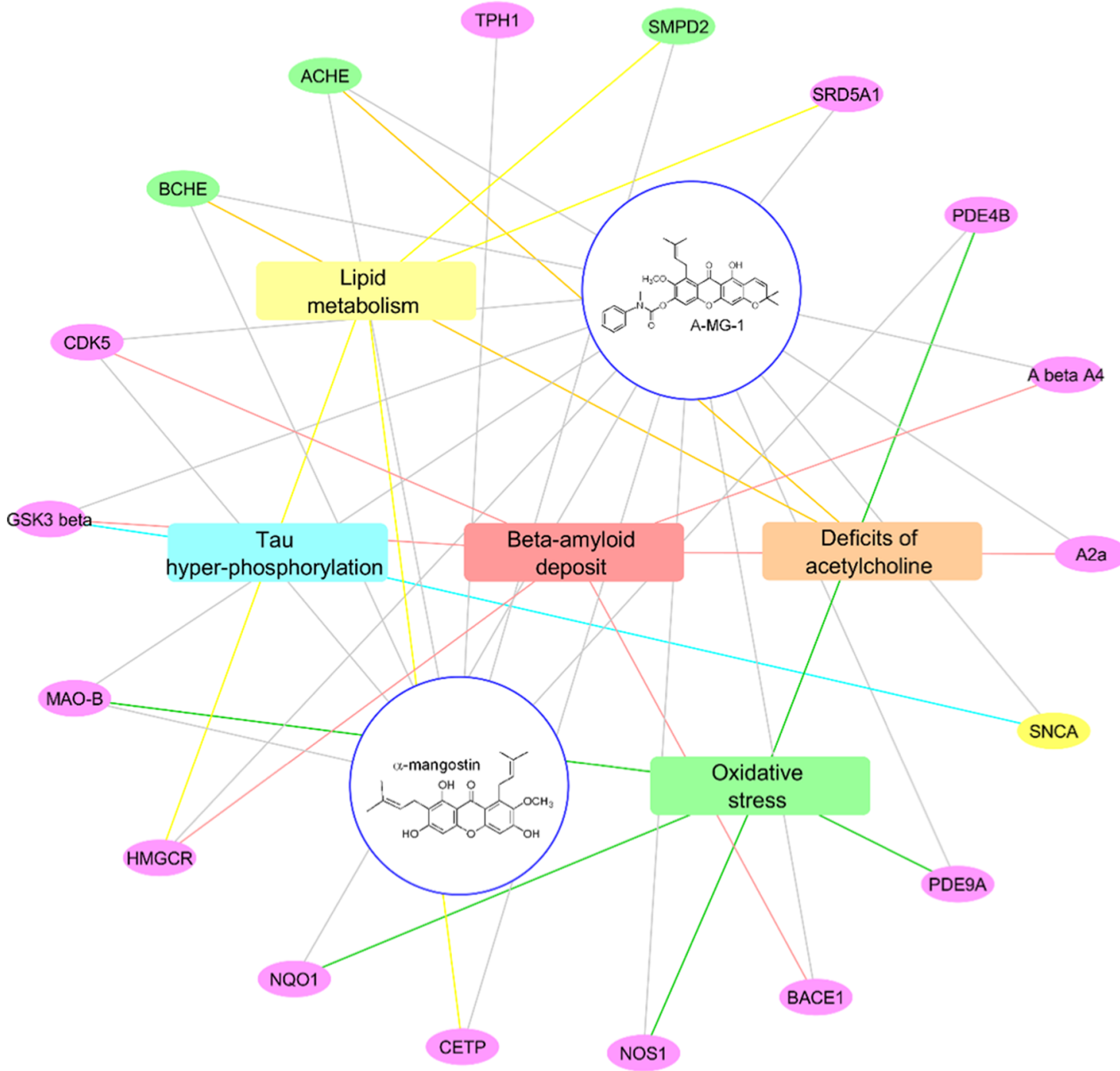

Figure 9. AD-specific target-disease network. Pink nodes represent the purely predicted targets. Yellow nodes represent the experimentally validated targets. Green nodes represent the known targets. Targets are categorized into five AD pathology hypothesis groups, lipid metabolism, tau hyperphosphorylation, $\beta$-amyloid deposit, deficits of acetylcholine, and oxidative stress, with edges in the corresponding color.

pass the blood-brain barrier (BBB). Eight combinations of fingerprints and algorithms were calculated (Table 5) for both

\section{Table 5. BBB Permeability Prediction}

\begin{tabular}{lccr}
\multicolumn{1}{c}{ algorithms and fingerprints } & threshold & $\alpha$-mangostin & AMG-1 \\
SVM and MACCS & 0.02 & -0.046 & -0.094 \\
SVM and Openbabel (FP2) & 0 & 0.146 & 0.155 \\
SVM and Molprint 2D & 0 & 0.341 & 0.681 \\
SVM and PubChem & 0 & -0.070 & -0.135 \\
AdaBoost and MACCS & 0 & -4.006 & -0.070 \\
AdaBoost and Openbabel (FP2) & 0 & 8.623 & 9.675 \\
AdaBoost and Molprint 2D & 0 & -1.614 & 3.049 \\
AdaBoost and PubChem & 0 & 0.089 & 1.226
\end{tabular}

$\alpha$-mangostin and AMG-1 as specified in Materials and Methods. The lipophilicity was increased for AMG-1 $(c \log P$ $=7.83$ ) after the annulation and the substitution of two hydroxyl groups of $\alpha$-mangostin $(c \log P=6.07)$. Although the combination of SVM with different fingerprint types can result in contradictory predictions, the algorithm AdaBoost provided consistent results that AMG-1 can have a better chance to cross the BBB. The differences among the abilities for these two compounds to pass the BBB help explaining the distinctive neuroprotective effects to some extent. Both the compounds passed the pan-assay interference compounds (PAINS)Remover, indicating that there are no undesired substructural features. The toxic hazard estimation using Toxtree suggested no improved toxicity profile of AMG-1. Both compounds were estimated to have their toxic hazard high. The chemical modification should be considered to decrease the toxicity while maintaining or increasing the activity to move further.

\section{DISCUSSION}

For this work, the study began with the natural product, $\alpha$ mangostin. AMG-1 was designed and synthesized as a derivative for $\alpha-\mathrm{M}$ in an effort to reduce the toxicity and increase the lipophilicity. Notably, the cyclization significantly reduced the toxicity of $\alpha-\mathrm{M}$, while the improved neuroprotective activities after the cyclization can also be observed at the cell level. Animal behavior studies using an open-field test and a Morris water maze showed that AMG-1 treatment can improve the memory loss and cognitive function in $\mathrm{A} \beta$ induced rats. After the sacrifice of the animals, multiple 
staining methods, including HE staining, Nissl staining, and Bielschowsky silver staining, were applied to brain slices for mechanism studies. The AMG-1 treatment can (1) have neuron cells with better morphology and density compared with the disease model, (2) significantly prevent the neuronal loss in $\mathrm{A} \beta$-induced $\mathrm{AD}$ rats, and (3) reduce the senile plaque and repair the neuron injury in the $\mathrm{AD}$ model. The quantification of immunohistochemical staining further demonstrated that the AMG-1 treatment significantly reduced the expression of $\mathrm{A} \beta_{1-42}$. A computational systems pharmacology analysis using the chemogenomics knowledgebase was applied for network studies. Compound-target, target-pathway, and target-disease networks were constructed, integrating both in silico analysis and reported experimental data. The systematic network analysis (1) confirmed the broad therapeutic spectrum of $\alpha$-mangostin, (2) bridged the corresponding targets with specific pathways and diseases, and (3) speculated that AMG-1 can demonstrate its therapeutic effects in a onemolecule, multiple-targets manner. In a nutshell, AMG-1 is reported here to be a promising compound with the potential for future modification and development for the study of Alzheimer's disease.

\section{MATERIALS AND METHODS}

All chemicals, reagents, and solvents were purchased from commercial suppliers and used without further purification unless otherwise noted. Isolation and reactions were monitored by analytical thin-layer chromatography (TLC) on silica gel 60 F254 percolated plates with a fluorescent indicator (purchased from Qingdao Haiyang Inc.). Visualization on TLC was achieved by UV light (254 or $365 \mathrm{~nm}$ ) and a typical TLC indicator solution ( $10 \%$ sulfuric acid/ethanol solution). Column chromatography was performed on silica gel (200300 mesh) for the purification of intermediates and final compounds. ${ }^{1} \mathrm{H}$ NMR and ${ }^{13} \mathrm{C}$ NMR spectra were recorded on a Bruker Avance $(500 \mathrm{MHz})$ spectrometer at $300 \mathrm{~K}$ in $\mathrm{CD}_{3} \mathrm{COCD}_{3}$ or $\mathrm{CDCl}_{3}$ with tetramethylsilane (TMS) as an internal standard. Chemical shifts are reported in ppm $(\delta)$; coupling constants $(J)$ are given in hertz; and peak multiplicities are reported as singlet $(\mathrm{s})$, doublet $(\mathrm{d})$, triplet $(\mathrm{t})$, and multiplet $(\mathrm{m})$. The electrospray ionization mass spectrometry (ESI-MS) and high-resolution ESI-MS data were recorded on an Agilent-6210-LC/TOF mass spectrometer. All final compounds were more than $95 \%$ pure, which was analyzed by a high-performance liquid chromatography (HPLC) system (Waters Corporation, Milford, MA). $\alpha$-Mangostin was isolated from the pericarp of G. mangostana, as reported in the literature. $^{33}$

General Procedures for the Synthesis and Spectral Data of the Synthesized Compounds. General Procedure for the Synthesis of $2 a-2 r$ and 3. To a solution of compound $1(0.01 \mathrm{mmol})$ and $\mathrm{K}_{2} \mathrm{CO}_{3}(0.012 \mathrm{mmol})$ in acetone, $\mathrm{CH}_{3} \mathrm{I}$ or $\mathrm{C}_{2} \mathrm{H}_{5} \mathrm{Br}(0.011 \mathrm{mmol})$ was added dropwise. The reaction mixture was heated to reflux for $12 \mathrm{~h}$. Then, the mixture was filtrated and the filtrate was concentrated to afford the crude product. The crude product was chromatographed on silica gel (petroleum ether $(\mathrm{PE}) / \mathrm{EtOAc}=40: 1, \mathrm{v} / \mathrm{v})$ to give compounds 2 and 3 as colorless oils (isolated yield 80.091.2\%).

Synthesis of AMG (4). To a solution of $\alpha-\mathrm{M}(4.0 \mathrm{mmol})$ in toluene, 2, 3-dicyano-5, 6-dichlorobenzoquinone (DDQ) (8.0 $\mathrm{mmol})$ was added at ice bath conditions and stirred at $40{ }^{\circ} \mathrm{C}$ for $5 \mathrm{~h}$. The reaction mixture was evaporated to remove toluene. Then, the crude product was purified by silica gel chromatography $(\mathrm{PE} / \mathrm{EtOAc}=10: 1)$ to afford 3 (isolated yield $85.0 \%)$.

General Procedure for the Synthesis of AMG-1-AMG-16. BTC $(0.20 \mathrm{mmol})$ was added to $10 \mathrm{~mL}$ of anhydrous $\mathrm{CH}_{2} \mathrm{Cl}_{2}$. A solution of 2 or $3(0.20 \mathrm{mmol})$ and $\mathrm{Et}_{3} \mathrm{~N}(0.18 \mathrm{mmol})$ in 5 $\mathrm{mL}$ of anhydrous $\mathrm{CH}_{2} \mathrm{Cl}_{2}$ was added dropwise to the above mixture at ice bath conditions and stirred at room temperature for another $4 \mathrm{~h}$. Then, a solution of AMG or BMG (0.1 mol) and 4-dimethylaminopyridine (DMAP, catalytic amount) in 5 $\mathrm{mL}$ of anhydrous $\mathrm{CH}_{2} \mathrm{Cl}_{2}$ was added dropwise to the above mixture at ice bath conditions. After a $6 \mathrm{~h}$ reaction at room temperature, the reaction mixture was diluted with $\mathrm{H}_{2} \mathrm{O}$ and extracted with EtOAc. The organic layers were then combined and washed with brine and dried over anhydrous $\mathrm{Na}_{2} \mathrm{SO}_{4}$. The solution was evaporated to afford the crude product. Then, the crude product was purified by silica gel column chromatography $(\mathrm{PE} / \mathrm{EtOAc}=20: 1)$ to give AMG-1-AMG-16 as a yellow solid (isolation yield $70.0-85.0 \%$ ).

5-Hydroxy-8-methoxy-2,2-dimethyl-7-(3-methylbut-2-en1-yl)-6-oxo-2,6-dihydropyrano[3,2-b]xanthen-9-yl methyl(phenyl)carbamate (AMG-1). ${ }^{1} \mathrm{H} \mathrm{NMR}\left(\mathrm{CDCl}_{3} 500 \mathrm{MHz}\right)$ : $\delta 13.55(1 \mathrm{H}, \mathrm{s}, 5-\mathrm{OH}), 7.46-7.40(4 \mathrm{H}, \mathrm{m}, \mathrm{Ar}-\mathrm{H}), 7.32(1 \mathrm{H}, \mathrm{t}$, $7.8 \mathrm{~Hz}, \mathrm{Ar}-\mathrm{H}), 7.28$ (1H, s, H-1), $6.74(1 \mathrm{H}, \mathrm{d}, J=10.2 \mathrm{~Hz}, \mathrm{H}-$ 9), $6.26(1 \mathrm{H}, \mathrm{s}, \mathrm{H}-8), 5.59(1 \mathrm{H}, \mathrm{d}, J=10.1 \mathrm{~Hz}, \mathrm{H}-10), 5.20$ (1H, brs, H-15), $4.12(2 \mathrm{H}, \mathrm{d}, J=4.0 \mathrm{~Hz}, \mathrm{H}-14), 3.46(3 \mathrm{H}, \mathrm{s}$, $\left.\mathrm{OCH}_{3}\right), 3.39\left(3 \mathrm{H}, \mathrm{s}, \mathrm{N}-\mathrm{CH}_{3}\right), 1.83\left(3 \mathrm{H}, \mathrm{s}, \mathrm{H}_{3}-18\right), 1.68(3 \mathrm{H}, \mathrm{s}$, $\left.\mathrm{H}_{3}-17\right), 1.48\left(6 \mathrm{H}, \mathrm{s}, \mathrm{H}_{3}-12\right.$ and $\left.\mathrm{H}_{3}-13\right) .{ }^{13} \mathrm{C}$ NMR: $\delta$ 182.2, 160.3 , 158.0, 156.4, 153.8, 152.4, 149.5, 146.7, 142.5, 138.5, $131.9,130.9,129.6,129.3,127.2,123.1,116.3,115.6,110.4$, 104.5, 104.0, 94.2, 78.1, 61.6, 38.6, 28.4, 28.4, 26.3, 25.8, 19.2. ESI-MS $m / z(\%): 540[\mathrm{M}-\mathrm{H}]^{-}$.

5-Hydroxy-8-methoxy-2,2-dimethyl-7-(3-methylbut-2-en1-yl)-6-oxo-2,6-dihydropyrano[3,2-b]xanthen-9-yl ethyl(phenyl)carbamate (AMG-2). ${ }^{1} \mathrm{H}$ NMR $\left(\mathrm{CD}_{3} \mathrm{COCD}_{3} 500\right.$ $\mathrm{MHz}): \delta 13.55(1 \mathrm{H}, \mathrm{s}, 5-\mathrm{OH}), 7.45-7.36(5 \mathrm{H}, \mathrm{m}, \mathrm{Ar}-\mathrm{H}), 7.38$ $(1 \mathrm{H}, \mathrm{s}, \mathrm{H}-1), 6.70(1 \mathrm{H}, \mathrm{d}, J=10.1 \mathrm{~Hz}, \mathrm{H}-9), 6.29(1 \mathrm{H}, \mathrm{s}, \mathrm{H}-$ 8), $5.74(1 \mathrm{H}, \mathrm{d}, J=10.1 \mathrm{~Hz}, \mathrm{H}-10), 5.22$ (1H, brs, H-15), 4.10 $(2 \mathrm{H}, \mathrm{d}, J=5.0 \mathrm{~Hz}, \mathrm{H}-14), 3.86\left(3 \mathrm{H}, \mathrm{s}, \mathrm{OCH}_{3}\right), 3.60(2 \mathrm{H}, \mathrm{q}, J$ $\left.=8.0 \mathrm{~Hz}, \mathrm{~N}-\mathrm{CH}_{2}\right), 1.81\left(3 \mathrm{H}, \mathrm{s}, \mathrm{H}_{3}-18\right), 1.65\left(3 \mathrm{H}, s, \mathrm{H}_{3}-17\right)$, $1.48\left(6 \mathrm{H}, \mathrm{s}, \mathrm{H}_{3}-12\right.$ and $\left.\mathrm{H}_{3}-13\right), 1.08(3 \mathrm{H}, t, J=8.0 \mathrm{~Hz}) .{ }^{13} \mathrm{C}$ NMR: $\delta 182.3,160.3,157.8,156.1,153.9,152.1,150.1,146.8$, $141.1,138.4,130.9,129.3,128.3,127.7,126.6,123.2,115.6$, 110.4, 104.6, 104.1, 94.2, 78.0, 61.5, 52.7, 46.2, 28.4, 28.4, 26.4, 25.6, 18.2, 12.8. ESI-MS $m / z(\%): 556[\mathrm{M}+\mathrm{H}]^{+}$.

5-Hydroxy-8-methoxy-2,2-dimethyl-7-(3-methylbut-2-en1-yl)-6-oxo-2,6-dihydropyrano[3,2-b]xanthen-9-yl methyl(otolyl)carbamate (AMG-3). ${ }^{1} \mathrm{H}$ NMR $\left(\mathrm{CDCl}_{3} 500 \mathrm{MHz}\right): \delta$ $13.55(1 \mathrm{H}, \mathrm{s}, 5-\mathrm{OH}), 7.32-7.27(4 \mathrm{H}, \mathrm{m}, \mathrm{Ar}-\mathrm{H}), 7.28(1 \mathrm{H}, \mathrm{s}$, $\mathrm{H}-1), 6.74(1 \mathrm{H}, \mathrm{d}, J=10.0 \mathrm{~Hz}, \mathrm{H}-9), 6.26(1 \mathrm{H}, \mathrm{s}, \mathrm{H}-8), 5.58$ $(1 \mathrm{H}, \mathrm{d}, J=10.0 \mathrm{~Hz}, \mathrm{H}-10), 5.17(1 \mathrm{H}, \mathrm{t}, J=5.5 \mathrm{~Hz}, \mathrm{H}-15)$, $4.12(2 \mathrm{H}, \mathrm{d}, J=5.5 \mathrm{~Hz}, \mathrm{H}-14), 3.36\left(3 \mathrm{H}, \mathrm{s}, \mathrm{OCH}_{3}\right), 3.35(3 \mathrm{H}$, s, $\left.\mathrm{N}-\mathrm{CH}_{3}\right), 2.11\left(3 \mathrm{H}, \mathrm{s}, \mathrm{Ar}-\mathrm{CH}_{3}\right) 1.81\left(3 \mathrm{H}, \mathrm{s}, \mathrm{H}_{3}-18\right), 1.66$ $\left(3 \mathrm{H}, \mathrm{s}, \mathrm{H}_{3}-17\right), 1.48\left(6 \mathrm{H}, \mathrm{s}, \mathrm{H}_{3}-12\right.$ and $\left.\mathrm{H}_{3}-13\right) .{ }^{13} \mathrm{C}$ NMR: $\delta$ $183.4,161.5,159.0,157.5,154.7,152.0,151.3,146.6,139.0$, $132.1,131.1,129.0,128.8,127.4,127.2,126.4,123.1,121.4$, $116.1,115.6,110.1,104.5,104.0,94.1,78.1,61.3,38.8,28.4$, 28.4, 27.0, 26.0, 21.1, 18.2. ESI-MS $m / z: 554[\mathrm{M}-\mathrm{H}]^{-}$.

5-Hydroxy-8-methoxy-2,2-dimethyl-7-(3-methylbut-2-en1-yl)-6-oxo-2,6-dihydropyrano[3,2-b]xanthen-9-ylmethyl(mtolyl)carbamate (AMG-4). ${ }^{1} \mathrm{H}$ NMR $\left(\mathrm{CD}_{3} \mathrm{COCD}_{3} 500\right.$ $\mathrm{MHz}): \delta 13.63(1 \mathrm{H}, \mathrm{s}, 5-\mathrm{OH}), 7.47-7.31(4 \mathrm{H}, \mathrm{m}, \mathrm{Ar}-\mathrm{H})$, $7.38(1 \mathrm{H}, \mathrm{s}, \mathrm{H}-1), 6.70(1 \mathrm{H}, \mathrm{d}, J=10.0 \mathrm{~Hz}, \mathrm{H}-9), 6.31(1 \mathrm{H}, \mathrm{s}$, 
$\mathrm{H}-8), 5.73(1 \mathrm{H}, \mathrm{d}, J=10.0 \mathrm{~Hz}, \mathrm{H}-10), 5.26(1 \mathrm{H}, \mathrm{t}, J=5.5 \mathrm{~Hz}$, $\mathrm{H}-15), 4.17(2 \mathrm{H}, \mathrm{d}, J=5.5 \mathrm{~Hz}, \mathrm{H}-14), 3.16\left(3 \mathrm{H}, \mathrm{s}, \mathrm{OCH}_{3}\right)$, $2.83\left(3 \mathrm{H}, \mathrm{s}, \mathrm{N}-\mathrm{CH}_{3}\right), 2.07\left(3 \mathrm{H}, \mathrm{s}, \mathrm{Ar}-\mathrm{CH}_{3}\right), 1.83\left(3 \mathrm{H}, \mathrm{s}, \mathrm{H}_{3}-\right.$ 18), $1.67\left(3 \mathrm{H}, \mathrm{s}, \mathrm{H}_{3}-17\right), 1.49\left(6 \mathrm{H}, \mathrm{s}, \mathrm{H}_{3}-12\right.$ and $\left.\mathrm{H}_{3}-13\right) .{ }^{13} \mathrm{C}$ NMR: $\delta 183.4,161.6,159.0,157.6,154.8,152.4,148.1,146.7$, $142.4,139.2$, 138.4, 132.1, 129.8, 129.0, 127.1, 123.2, 123.2, $116.2,115.9,115.6,111.9,105.1,104.7,95.0,79.2,62.2,38.6$, 28.4, 28.4, 26.3, 25.8, 21.3, 18.2. ESI-MS $m / z: 556[\mathrm{M}+\mathrm{H}]^{+}$.

5-Hydroxy-8-methoxy-2,2-dimethyl-7-(3-methylbut-2-en1-yl)-6-oxo-2,6-dihydropyrano[3,2-b]xanthen-9-ylmethyl(ptolyl)carbamate (AMG-5). ${ }^{1} \mathrm{H}$ NMR $\left(\mathrm{CDCl}_{3} 500 \mathrm{MHz}\right): \delta$ 13.55 (1H, s, 5-OH), $7.29(2 \mathrm{H}, \mathrm{d}, J=8.0 \mathrm{~Hz}, \mathrm{Ar}-\mathrm{H}), 7.28(1 \mathrm{H}$, s, H-1), $7.22(2 \mathrm{H}, \mathrm{d}, J=8.0 \mathrm{~Hz}, \mathrm{Ar}-\mathrm{H}), 6.74(1 \mathrm{H}, \mathrm{d}, J=10.0$ $\mathrm{Hz}, \mathrm{H}-9), 6.26$ (1H, s, H-8), $5.73(1 \mathrm{H}, \mathrm{d}, J=10.0 \mathrm{~Hz}, \mathrm{H}-10)$, 5.25 (1H, brs, H-15), $4.17(2 \mathrm{H}, \mathrm{d}, J=3.5 \mathrm{~Hz}, \mathrm{H}-14), 3.19$ $\left(3 \mathrm{H}, \mathrm{s}, \mathrm{OCH}_{3}\right), 3.11\left(3 \mathrm{H}, \mathrm{s}, \mathrm{N}-\mathrm{CH}_{3}\right), 2.38\left(3 \mathrm{H}, \mathrm{s}, \mathrm{Ar}-\mathrm{CH}_{3}\right)$, $1.83\left(3 \mathrm{H}, \mathrm{s}, \mathrm{H}_{3}-18\right), 1.67$ (3H, s, $\left.\mathrm{H}_{3}-17\right), 1.48\left(6 \mathrm{H}, \mathrm{s}, \mathrm{H}_{3}-12\right.$ and $\left.\mathrm{H}_{3}-13\right) .{ }^{13} \mathrm{C}$ NMR: $\delta$ 177.4, 157.7, 156.2, 152.8, 152.7, $152.6,149.6,148.0,146.6,138.4,131.9,129.9,129.8,126.3$, 123.6, 118.7, 116.2, 111.9, 110.9, 110.2, 110.0, 99.6, 77.6, 62.4, $38.6,28.3,28.3,26.1,25.8,21.0,18.1$. ESI-MS $\mathrm{m} / z$ (\%): 556 $[\mathrm{M}+\mathrm{H}]^{+}$.

5-Hydroxy-8-methoxy-2,2-dimethyl-7-(3-methylbut-2-en1-yl)-6-oxo-2,6-dihydropyrano[3,2-b]xanthen-9-yl(2methoxyphenyl)(methyl)carbamate (AMG-6). ${ }^{1} \mathrm{H}$ NMR $\left(\mathrm{CDCl}_{3} 500 \mathrm{MHz}\right): \delta 13.55(1 \mathrm{H}, \mathrm{s}, 5-\mathrm{OH}), 7.34(2 \mathrm{H}, \mathrm{m}$, Ar-H), 7.28 (1H, s, H-1), $7.00(2 \mathrm{H}, \mathrm{m}, \mathrm{Ar}-\mathrm{H}), 6.74(1 \mathrm{H}, \mathrm{d}, J=$ $10.0 \mathrm{~Hz}, \mathrm{H}-9), 6.26(1 \mathrm{H}, \mathrm{s}, \mathrm{H}-8), 5.68(1 \mathrm{H}, \mathrm{d}, J=10.0 \mathrm{~Hz}, \mathrm{H}-$ 10), $5.17(1 \mathrm{H}, \mathrm{t}, J=5.5 \mathrm{~Hz}, \mathrm{H}-15), 4.06(2 \mathrm{H}, \mathrm{d}, J=5.5 \mathrm{~Hz}, \mathrm{H}-$ 14), $3.92\left(3 \mathrm{H}, \mathrm{s}, \mathrm{OCH}_{3}\right), 3.49\left(3 \mathrm{H}, \mathrm{s}, \mathrm{OCH}_{3}\right), 3.42(3 \mathrm{H}, \mathrm{s}, \mathrm{N}-$ $\left.\mathrm{CH}_{3}\right), 1.83\left(3 \mathrm{H}, \mathrm{s}, \mathrm{H}_{3}-18\right), 1.66\left(3 \mathrm{H}, \mathrm{s}, \mathrm{H}_{3}-17\right), 1.47(6 \mathrm{H}, \mathrm{s}$, $\mathrm{H}_{3}-12$ and $\left.\mathrm{H}_{3}-13\right) .{ }^{13} \mathrm{C}$ NMR: $\delta 182.3,160.2,158.0,156.4$, $155.1,153.2$, 153.0, 149.8, 146.6, 138.2, 131.8, 131.0, 129.2, $128.8,127.1,123.0,120.8,115.9,115.6,111.8,110.1,104.5$, 104.0, 94.1, 78.0, 61.2, 55.6, 37.7, 28.4, 28.4, 26.3, 25.8, 18.1 . ESI-MS $m / z: 572[\mathrm{M}+\mathrm{H}]^{+}$.

5-Hydroxy-8-methoxy-2,2-dimethyl-7-(3-methylbut-2-en1-yl)-6-oxo-2,6-dihydropyrano[3,2-b]xanthen-9-yl(3methoxyphenyl)(methyl)carbamate (AMG-7). ${ }^{1} \mathrm{H}$ NMR $\left(\mathrm{CDCl}_{3} 500 \mathrm{MHz}\right): \delta 13.55(1 \mathrm{H}, \mathrm{s}, 5-\mathrm{OH}), 7.35-7.25(2 \mathrm{H}$, m, Ar-H), 7.28 (1H, s, H-1), 7.02-6.87 (2H, m, Ar-H), 6.74 $(1 \mathrm{H}, \mathrm{d}, J=10.0 \mathrm{~Hz}, \mathrm{H}-9), 6.26(1 \mathrm{H}, \mathrm{s}, \mathrm{H}-8), 5.68(1 \mathrm{H}, \mathrm{d}, J=$ $10.0 \mathrm{~Hz}, \mathrm{H}-10), 5.16(1 \mathrm{H}$, brs, H-15), $4.11(2 \mathrm{H}, \mathrm{d}, J=3.5 \mathrm{~Hz}$, $\mathrm{H}-14), 3.84\left(3 \mathrm{H}, \mathrm{s}, \mathrm{OCH}_{3}\right), 3.49\left(3 \mathrm{H}, \mathrm{s}, \mathrm{OCH}_{3}\right), 3.45(3 \mathrm{H}, \mathrm{s}$, $\left.\mathrm{N}-\mathrm{CH}_{3}\right), 1.83\left(3 \mathrm{H}, \mathrm{s}, \mathrm{H}_{3}-18\right), 1.63\left(3 \mathrm{H}, \mathrm{s}, \mathrm{H}_{3}-17\right), 1.49(6 \mathrm{H}, \mathrm{s}$, $\mathrm{H}_{3}-12$ and $\left.\mathrm{H}_{3}-13\right) .{ }^{13} \mathrm{C}$ NMR: $\delta 182.2,160.3,160.2,158.0$, $156.4,153.8,152.4,149.5,146.7,143.6,138.5,131.9,129.9$, $127.3,127.2,123.2,123.1,116.3,115.6,112.6,110.5,104.5$, 104.0, 94.2, 78.1, 61.2, 55.5, 38.6, 28.4, 28.4, 26.4, 25.8, 18.2. ESI-MS $m / z: 572[\mathrm{M}+\mathrm{H}]^{+}$.

5-Hydroxy-8-methoxy-2,2-dimethyl-7-(3-methylbut-2-en1-yl)-6-oxo-2,6-dihydropyrano[3,2-b]xanthen-9-yl(4methoxyphenyl)(methyl)carbamate (AMG-8). ${ }^{1} \mathrm{H}$ NMR $\left(\mathrm{CDCl}_{3} 500 \mathrm{MHz}\right): \delta 13.55(1 \mathrm{H}, \mathrm{s}, 5-\mathrm{OH}), 7.32(2 \mathrm{H}, \mathrm{d}, J=$ $8.0 \mathrm{~Hz}, \mathrm{Ar}-\mathrm{H}), 7.27$ (1H, s, H-1), $6.94(2 \mathrm{H}, \mathrm{d}, J=8.0 \mathrm{~Hz}, \mathrm{Ar}-$ $\mathrm{H}), 6.74(1 \mathrm{H}, \mathrm{d}, J=10.0 \mathrm{~Hz}, \mathrm{H}-9), 6.26(1 \mathrm{H}, \mathrm{s}, \mathrm{H}-8), 5.58$ $(1 \mathrm{H}, \mathrm{d}, J=10.0 \mathrm{~Hz}, \mathrm{H}-10), 5.18(1 \mathrm{H}, \mathrm{brs}, \mathrm{H}-15), 4.11(2 \mathrm{H}, \mathrm{d}$, $J=3.5 \mathrm{~Hz}, \mathrm{H}-14), 3.83\left(3 \mathrm{H}, \mathrm{s}, \mathrm{OCH}_{3}\right), 3.48\left(3 \mathrm{H}, \mathrm{s}, \mathrm{OCH}_{3}\right)$, $3.38\left(3 \mathrm{H}, \mathrm{s}, \mathrm{N}-\mathrm{CH}_{3}\right), 1.82\left(3 \mathrm{H}, \mathrm{s}, \mathrm{H}_{3}-18\right), 1.67\left(3 \mathrm{H}, \mathrm{s}, \mathrm{H}_{3}-17\right)$, $1.48\left(6 \mathrm{H}, \mathrm{s}, \mathrm{H}_{3}-12\right.$ and $\left.\mathrm{H}_{3}-13\right) .{ }^{13} \mathrm{C}$ NMR: $\delta 182.2,160.2$, $159.7,158.0,156.4,153.8,152.7,149.5,146.7,138.4,131.9$, $127.7,127.2$, 123.2, 123.1, 116.2, 115.6, 114.5, 110.5, 104.5,
104.0, 94.1, 78.1, 61.6, 55.5, 38.9, 28.4, 28.4, 26.3, 25.8, 18.2. ESI-MS $m / z(\%): 570[\mathrm{M}-\mathrm{H}]^{-}$.

5-Hydroxy-8-methoxy-2,2-dimethyl-7-(3-methylbut-2-en1-yl)-6-oxo-2,6-dihydropyrano[3,2-b]xanthen-9-yl(3ethylphenyl)(methyl)carbamate (AMG-9). ${ }^{1} \mathrm{H}$ NMR $\left(\mathrm{CD}_{3} \mathrm{COCD}_{3} 500 \mathrm{MHz}\right): \delta 13.55(1 \mathrm{H}, s, 5-\mathrm{OH}), 7.35-7.14$ $(4 \mathrm{H}, \mathrm{m}, \mathrm{Ar}-\mathrm{H}), 7.26(1 \mathrm{H}, \mathrm{s}, \mathrm{H}-1), 6.73(1 \mathrm{H}, d, J=10.0 \mathrm{~Hz}, \mathrm{H}-$ 9), $6.25(1 \mathrm{H}, \mathrm{s}, \mathrm{H}-8), 5.58(1 \mathrm{H}, \mathrm{d}, J=10.0 \mathrm{~Hz}, \mathrm{H}-10), 5.20$ $(1 \mathrm{H}, \mathrm{brs}, \mathrm{H}-15), 4.11(2 \mathrm{H}, \mathrm{d}, J=3.5 \mathrm{~Hz}, \mathrm{H}-14), 3.50(3 \mathrm{H}, \mathrm{s}$, $\left.\mathrm{OCH}_{3}\right), 3.46\left(3 \mathrm{H}, \mathrm{s}, \mathrm{N}-\mathrm{CH}_{3}\right), 2.68\left(2 \mathrm{H}, \mathrm{m}, \mathrm{Ar}-\mathrm{CH}_{2}\right), 1.82$ $\left(3 \mathrm{H}, \mathrm{s}, \mathrm{H}_{3}-18\right), 1.67\left(3 \mathrm{H}, \mathrm{s}, \mathrm{H}_{3}-17\right), 1.48\left(6 \mathrm{H}, \mathrm{s}, \mathrm{H}_{3}-12\right.$ and $\left.\mathrm{H}_{3}-13\right), 1.26\left(3 \mathrm{H}, \mathrm{t}, J=7.5 \mathrm{~Hz}, \mathrm{CH}_{3}\right) .{ }^{13} \mathrm{C}$ NMR: $\delta 182.3$, $160.3,158.0,156.4,153.8,152.6,149.6,146.6,145.6,142.5$, $138.5,131.9,129.1,127.2,127.2,123.0,123.0,116.2,115.6$, $115.6,110.4,104.5,104.0,94.2,78.1,61.6,38.4,30.9,28.4$, 28.4, 26.4, 25.8, 18.2, 15.4. ESI-MS: $568[\mathrm{M}-\mathrm{H}]^{-}$.

5-Hydroxy-8-methoxy-2,2-dimethyl-7-(3-methylbut-2-en1-yl)-6-oxo-2,6-dihydropyrano[3,2-b]xanthen-9-yl(3chlorophenyl)(methyl)carbamate (AMG-10). ${ }^{1} \mathrm{H}$ NMR $\left(\mathrm{CDCl}_{3} 500 \mathrm{MHz}\right): \delta 13.52(1 \mathrm{H}, s, 5-\mathrm{OH}), 7.47(1 \mathrm{H}, \mathrm{d}, J=$ $1.5 \mathrm{~Hz}, \mathrm{Ar}-\mathrm{H}), 7.44-7.31(2 \mathrm{H}, \mathrm{m}, \mathrm{Ar}-\mathrm{H}), 7.28(1 \mathrm{H}, \mathrm{s}, \mathrm{H}-1)$, $7.24(1 \mathrm{H}, \mathrm{m}, \mathrm{Ar}-\mathrm{H}), 6.73(1 \mathrm{H}, d, J=10.0 \mathrm{~Hz}, \mathrm{H}-9), 6.26(1 \mathrm{H}$, s, H-8), $5.58(1 \mathrm{H}, \mathrm{d}, J=10.0 \mathrm{~Hz}, \mathrm{H}-10), 5.21$ (1H, brs, H-15), $4.12(2 \mathrm{H}, \mathrm{d}, J=5.5 \mathrm{~Hz}, \mathrm{H}-14), 3.56\left(3 \mathrm{H}, \mathrm{s}, \mathrm{OCH}_{3}\right), 3.46(3 \mathrm{H}$, s, $\left.\mathrm{N}-\mathrm{CH}_{3}\right), 1.83\left(3 \mathrm{H}, \mathrm{s}, \mathrm{H}_{3}-18\right), 1.68\left(3 \mathrm{H}, \mathrm{s}, \mathrm{H}_{3}-17\right), 1.48(6 \mathrm{H}$, s, $\mathrm{H}_{3}-12$ and $\left.\mathrm{H}_{3}-13\right) .{ }^{13} \mathrm{C}$ NMR: $\delta$ 182.2, $160.3,158.0,156.4$, $153.8,152.4,149.2,146.7,143.6,138.7,134.7,134.7,132.1$, 130.2 , 127.3, 123.1, 123.0, 116.5, 115.7, 115.6, 110.5, 104.5, 104.0, 94.2, 78.1, 61.7, 38.4, 28.4, 28.4, 26.3, 25.8, 18.2. ESIMS $m / z: 574[\mathrm{M}-\mathrm{H}]^{-}$.

5-Hydroxy-8-methoxy-2,2-dimethyl-7-(3-methylbut-2-en1-yl)-6-oxo-2,6-dihydropyrano[3,2-b]xanthen-9-yl(4chlorophenyl)(methyl)carbamaten (AMG-11). ${ }^{1} \mathrm{H}$ NMR $\left(\mathrm{CDCl}_{3} 500 \mathrm{MHz}\right): \delta 7.40(2 \mathrm{H}, \mathrm{d}, J=8.5 \mathrm{~Hz}, \mathrm{Ar}-\mathrm{H}), 7.36$ $(2 \mathrm{H}, \mathrm{d}, J=8.5 \mathrm{~Hz}, \mathrm{Ar}-\mathrm{H}), 7.28(1 \mathrm{H}, \mathrm{s}, \mathrm{H}-1), 6.73(1 \mathrm{H}, d, J=$ $10.0 \mathrm{~Hz}, \mathrm{H}-9), 6.26(1 \mathrm{H}, \mathrm{s}, \mathrm{H}-8), 5.58(1 \mathrm{H}, \mathrm{d}, J=10.0 \mathrm{~Hz}, \mathrm{H}-$ 10), 5.20 (1H, brs, H-15), $4.11(2 \mathrm{H}, \mathrm{d}, J=5.5 \mathrm{~Hz}, \mathrm{H}-14), 3.50$ $\left(3 \mathrm{H}, \mathrm{s}, \mathrm{OCH}_{3}\right), 3.43\left(3 \mathrm{H}, \mathrm{s}, \mathrm{N}-\mathrm{CH}_{3}\right), 1.83\left(3 \mathrm{H}, \mathrm{s}, \mathrm{H}_{3}-18\right), 1.68$ $\left(3 \mathrm{H}, \mathrm{s}, \mathrm{H}_{3}-17\right), 1.48\left(6 \mathrm{H}, \mathrm{s}, \mathrm{H}_{3}-12\right.$ and $\left.\mathrm{H}_{3}-13\right) .{ }^{13} \mathrm{C}$ NMR: $\delta$ 182.2 , 160.2, 158.0, 156.4, 153.7, 152.1, 149.3, 146.6, 141.2, $138.4,132.0,129.4,127.2,123.1,123.0,116.2,115.6,115.5$, $110.5,104.8,104.1,94.2,78.1,61.4,37.4,28.4,28.4,26.3,25.8$, 18.2. ESI-MS $m / z: 576[\mathrm{M}+\mathrm{H}]^{+}$.

5-Hydroxy-8-methoxy-2,2-dimethyl-7-(3-methylbut-2-en1-yl)-6-oxo-2,6-dihydropyrano[3,2-b]xanthen-9-yl(2bromophenyl)(methyl)carbamate (AMG-12). ${ }^{1} \mathrm{H}$ NMR $\left(\mathrm{CDCl}_{3} 500 \mathrm{MHz}\right): \delta 13.54(1 \mathrm{H}, s, 5-\mathrm{OH}), 7.48-7.71(1 \mathrm{H}$, d, $J=8.0 \mathrm{~Hz}, \mathrm{Ar}-\mathrm{H}), 7.47-7.42(2 \mathrm{H}, \mathrm{m}, \mathrm{Ar}-\mathrm{H}), 7.32(1 \mathrm{H}, \mathrm{s}$, $\mathrm{H}-1), 7.24(1 \mathrm{H}, \mathrm{d}, J=7.5 \mathrm{~Hz}, \mathrm{Ar}-\mathrm{H}), 6.73(1 \mathrm{H}, d, J=10.0 \mathrm{~Hz}$, H-9), 6.25 (1H, s, H-8), $5.58(1 \mathrm{H}, \mathrm{d}, J=10.0 \mathrm{~Hz}, \mathrm{H}-10), 5.17$ $(1 \mathrm{H}, \mathrm{t}, J=7.5 \mathrm{~Hz}, \mathrm{H}-15), 4.10(2 \mathrm{H}, \mathrm{d}, J=7.5 \mathrm{~Hz}, \mathrm{H}-14), 3.50$ $\left(3 \mathrm{H}, \mathrm{s}, \mathrm{OCH}_{3}\right), 3.37\left(3 \mathrm{H}, \mathrm{s}, \mathrm{N}-\mathrm{CH}_{3}\right), 1.81\left(3 \mathrm{H}, \mathrm{s}, \mathrm{H}_{3}-18\right), 1.66$ $\left(3 \mathrm{H}, \mathrm{s}, \mathrm{H}_{3}-17\right), 1.48\left(6 \mathrm{H}, \mathrm{s}, \mathrm{H}_{3}-12\right.$ and $\left.\mathrm{H}_{3}-13\right) .{ }^{13} \mathrm{C}$ NMR: $\delta$ $182.2,160.2,158.0,156.4,153.7,152.1,149.3,146.6,141.2$, $138.4,133.6,131.9,129.7,129.4,128.7,127.2,123.1,123.0$, $116.3,115.6,110.3,104.5,104.0,94.2,78.1,61.5,38.6,28.4$, 28.4, 26.4, 25.8, 18.2. ESI-MS $m / z: 620[\mathrm{M}+\mathrm{H}]^{+}$.

5-Hydroxy-8-methoxy-2,2-dimethyl-7-(3-methylbut-2-en1-yl)-6-oxo-2,6-dihydropyrano[3,2-b]xanthen-9-yl(3bromophenyl)(methyl)carbamate (AMG-13). ${ }^{1} \mathrm{H}$ NMR $\left(\mathrm{CDCl}_{3} 500 \mathrm{MHz}\right): \delta 13.52(1 \mathrm{H}, \mathrm{s}, 5-\mathrm{OH}), 7.46-7.60(1 \mathrm{H}$, d, $J=1.5 \mathrm{~Hz}, \mathrm{Ar}-\mathrm{H}), 7.45-7.24(3 \mathrm{H}, \mathrm{m}, \mathrm{Ar}-\mathrm{H}), 7.28(1 \mathrm{H}, \mathrm{s}$, $\mathrm{H}-1), 6.73(1 \mathrm{H}, d, J=10.0 \mathrm{~Hz}, \mathrm{H}-9), 6.26(1 \mathrm{H}, \mathrm{s}, \mathrm{H}-8), 5.58$ 
$(1 \mathrm{H}, \mathrm{d}, J=10.0 \mathrm{~Hz}, \mathrm{H}-10), 5.20$ (1H, brs, H-15), $4.11(2 \mathrm{H}, \mathrm{d}$, $J=4.0 \mathrm{~Hz}, \mathrm{H}-14), 3.49\left(3 \mathrm{H}, \mathrm{s}, \mathrm{OCH}_{3}\right), 3.43\left(3 \mathrm{H}, \mathrm{s}, \mathrm{N}-\mathrm{CH}_{3}\right)$, $1.83\left(3 \mathrm{H}, \mathrm{s}, \mathrm{H}_{3}-18\right), 1.68\left(3 \mathrm{H}, \mathrm{s}, \mathrm{H}_{3}-17\right), 1.48\left(6 \mathrm{H}, \mathrm{s}, \mathrm{H}_{3}-12\right.$ and $\left.\mathrm{H}_{3}-13\right) .{ }^{13} \mathrm{C}$ NMR: $\delta$ 182.1, 160.3, 158.0, 156.4, 153.8, 152.2 , 149.2, 146.7, 143.7, 138.6, 132.0, 130.5, 127.2, 127.2, $123.0,123.0,122.5,116.3,115.6,115.6,110.5,104.6,104.0$, $94.2,78.1,61.7,38.4,28.4,28.4,26.4,25.8,18.2$. ESI-MS $m / z$ : $620[\mathrm{M}+\mathrm{H}]^{+}$.

5-Hydroxy-8-methoxy-2,2-dimethyl-7-(3-methylbut-2-en1-yl)-6-oxo-2,6-dihydropyrano[3,2-b]xanthen-9-yl(4bromophenyl)(methyl)carbamate (AMG-14). ${ }^{1} \mathrm{H}$ NMR $\left(\mathrm{CDCl}_{3} 500 \mathrm{MHz}\right): \delta 13.52(1 \mathrm{H}, \mathrm{s}, 5-\mathrm{OH}), 7.55(2 \mathrm{H}, \mathrm{d}, J=$ $8.5 \mathrm{~Hz}, \mathrm{Ar}-\mathrm{H}), 7.28$ (1H, s, H-1), $7.23(2 \mathrm{H}, \mathrm{d}, J=8.5 \mathrm{~Hz}, \mathrm{Ar}-$ $\mathrm{H}), 6.73(1 \mathrm{H}, d, J=10.0 \mathrm{~Hz}, \mathrm{H}-9), 6.26(1 \mathrm{H}, \mathrm{s}, \mathrm{H}-8), 5.58$ $(1 \mathrm{H}, \mathrm{d}, J=10.0 \mathrm{~Hz}, \mathrm{H}-10), 5.19(1 \mathrm{H}, \mathrm{brs}, \mathrm{H}-15), 4.11(2 \mathrm{H}, \mathrm{d}$, $J=4.0 \mathrm{~Hz}, \mathrm{H}-14), 3.49\left(3 \mathrm{H}, \mathrm{s}, \mathrm{OCH}_{3}\right), 3.43\left(3 \mathrm{H}, \mathrm{s}, \mathrm{N}-\mathrm{CH}_{3}\right)$, $1.83\left(3 \mathrm{H}, \mathrm{s}, \mathrm{H}_{3}-18\right), 1.68\left(3 \mathrm{H}, \mathrm{s}, \mathrm{H}_{3}-17\right), 1.48\left(6 \mathrm{H}, \mathrm{s}, \mathrm{H}_{3}-12\right.$ and $\left.\mathrm{H}_{3}-13\right) .{ }^{13} \mathrm{C}$ NMR: $\delta 182.1,160.3,158.0,156.4,153.8$, 152.2 , 149.2, 146.7, 141.5, 138.6, 132.3, 132.0, 127.2, 123.0, 123.0, 116.3, 115.6, 115.6, 110.5, 104.5, 104.0, 94.2, 78.1, 61.7, 38.4, 28.4, 28.4, 26.3, 25.8, 18.2. ESI-MS $m / z: 618[\mathrm{M}-\mathrm{H}]^{-}$.

5-Hydroxy-8-methoxy-2,2-dimethyl-7-(3-methylbut-2-en1-yl)-6-oxo-2,6-dihydropyrano[3,2-b]xanthen-9-yl(4butylphenyl)(methyl)carbamate (AMG-15). ${ }^{1} \mathrm{H}$ NMR $\left(\mathrm{CDCl}_{3} 500 \mathrm{MHz}\right): \delta 13.55(1 \mathrm{H}, \mathrm{s}, 5-\mathrm{OH}), 7.29(2 \mathrm{H}, \mathrm{d}, J=$ $8.0 \mathrm{~Hz}, \mathrm{Ar}-\mathrm{H}), 7.28(1 \mathrm{H}, \mathrm{s}, \mathrm{H}-1), 7.23(2 \mathrm{H}, \mathrm{d}, J=8.0 \mathrm{~Hz}, \mathrm{Ar}-$ $\mathrm{H}), 6.74(1 \mathrm{H}, d, J=10.0 \mathrm{~Hz}, \mathrm{H}-9), 6.26(1 \mathrm{H}, \mathrm{s}, \mathrm{H}-8), 5.58$ $(1 \mathrm{H}, \mathrm{d}, J=10.0 \mathrm{~Hz}, \mathrm{H}-10), 5.19(1 \mathrm{H}, \mathrm{brs}, \mathrm{H}-15), 4.11(2 \mathrm{H}, \mathrm{d}$, $J=4.0 \mathrm{~Hz}, \mathrm{H}-14), 3.45\left(3 \mathrm{H}, \mathrm{s}, \mathrm{OCH}_{3}\right), 3.41\left(3 \mathrm{H}, \mathrm{s}, \mathrm{N}-\mathrm{CH}_{3}\right)$, $2.62\left(2 \mathrm{H}, \mathrm{t}, J=7.0 \mathrm{~Hz}, \mathrm{Ar}-\mathrm{CH}_{2}\right), 1.83\left(3 \mathrm{H}, \mathrm{s}, \mathrm{H}_{3}-18\right), 1.68$ $\left(3 \mathrm{H}, \mathrm{s}, \mathrm{H}_{3}-17\right), 1.60\left(2 \mathrm{H}, \mathrm{m}, \mathrm{CH}_{2}\right), 1.48\left(6 \mathrm{H}, \mathrm{s}, \mathrm{H}_{3}-12\right.$ and $\mathrm{H}_{3}-$ 13), $1.37\left(2 \mathrm{H}, \mathrm{m}, \mathrm{CH}_{2}\right), 0.94\left(3 \mathrm{H}, \mathrm{t}, J=7.0 \mathrm{~Hz}, \mathrm{CH}_{3}\right) .{ }^{13} \mathrm{C}$ NMR: $\delta 182.3,160.3,158.0,156.4,153.8,152.6,149.6,146.7$, $140.1,138.4,131.9,129.2,127.2,126.4,123.1,116.1,115.8$, $115.7,110.4,104.5,104.0,94.2,78.1,61.6,38.6,35.2,33.5$, $28.4,28.4,26.3,25.8,22.3,18.2,13.9$. ESI-MS $m / z: 596[\mathrm{M}-$ $\mathrm{H}]^{-}$.

5-Hydroxy-8-methoxy-2,2-dimethyl-7-(3-methylbut-2-en1-yl)-6-oxo-2,6-dihydropyrano[3,2-b]xanthen-9-yl(3ethoxyphenyl)(methyl)carbamate (AMG-16). ${ }^{1} \mathrm{H}$ NMR $\left(\mathrm{CDCl}_{3} 500 \mathrm{MHz}\right): \delta 13.55(1 \mathrm{H}, s, 5-\mathrm{OH}), 7.31-7.28(4 \mathrm{H}$, m, Ar-H), $7.24(1 \mathrm{H}, \mathrm{s}, \mathrm{H}-1), 6.74(1 \mathrm{H}, d, J=10.0 \mathrm{~Hz}, \mathrm{H}-9)$, $6.26(1 \mathrm{H}, \mathrm{s}, \mathrm{H}-8), 5.58(1 \mathrm{H}, \mathrm{d}, J=10.0 \mathrm{~Hz}, \mathrm{H}-10), 5.19(1 \mathrm{H}$, brs, $\mathrm{H}-15), 4.12(2 \mathrm{H}, \mathrm{d}, J=4.0 \mathrm{~Hz}, \mathrm{H}-14), 4.06(2 \mathrm{H}, \mathrm{q}, J=7.5$ $\left.\mathrm{Hz}, \mathrm{OCH}_{2} \mathrm{CH}_{3}\right), 3.49\left(3 \mathrm{H}, \mathrm{s}, \mathrm{OCH}_{3}\right), 3.44\left(3 \mathrm{H}, \mathrm{s}, \mathrm{N}-\mathrm{CH}_{3}\right)$, $1.83\left(3 \mathrm{H}, \mathrm{s}, \mathrm{H}_{3}-18\right), 1.68\left(3 \mathrm{H}, \mathrm{s}, \mathrm{H}_{3}-17\right), 1.48\left(6 \mathrm{H}, \mathrm{s}, \mathrm{H}_{3}-12\right.$ and $\left.\mathrm{H}_{3}-13\right), 1.26\left(3 \mathrm{H}, \mathrm{t}, J=7.5 \mathrm{~Hz}, \mathrm{OCH}_{2} \mathrm{CH}_{3}\right) .{ }^{13} \mathrm{C}$ NMR: $\delta$ $182.3,160.2,159.6,158.0,156.4,153.8,152.4,149.5,146.7$, $143.8,138.4,131.9,129.8,127.3,127.2,123.1,123.0,116.3$, 115.6, 113.2, 110.4, 104.5, 104.0, 94.2, 78.1, 61.6, 58.4, 38.6, 28.4, 28.4, 26.3, 25.8, 18.2, 14.7. ESI-MS $m / z: 584[\mathrm{M}-\mathrm{H}]^{-}$.

In Vitro Experiments. Neuroprotective Effect Assay. PC12 cells (pheochromocytoma) were obtained from the Chinese Academy of Medical Sciences, Shanghai Institutes for Biological Sciences. Cells were grown in a culture flask at a humidified atmosphere of $5 \% \mathrm{CO}_{2}$ and in Dulbecco's modified Eagle's medium (DMEM) containing 10\% fetal bovine serum supplemented with $100 \mathrm{U} / \mathrm{mL}$ penicillin/streptomycin at 37 ${ }^{\circ} \mathrm{C}$. The culture medium was changed every 2 days. Cells were seeded in 96-well plates $\left(3 \times 10^{4}\right.$ cells per well $) 48 \mathrm{~h}$ prior to treatment. All compounds were dissolved in dimethyl sulfoxide (DMSO), with the final concentration of DMSO less than $0.1 \%$. PC12 cells were pretreated with various concentrations of all compounds for $24 \mathrm{~h}$ and exposed to $300 \mu \mathrm{M} \mathrm{H}_{2} \mathrm{O}_{2}$ for an additional $12 \mathrm{~h}$. The control cells were treated with an equal amount of DMEM. Edaravone was set as a positive drug. The cell viability was assessed by the MTT assay. ${ }^{34}$

AChE Inhibition Assay. AChE inhibitory activity was studied using Ellman's method with slight modifications. ${ }^{35}$ Briefly, $220 \mu \mathrm{L}$ of an assay mixture containing $50 \mu \mathrm{L}$ of the sample solution, $140 \mu \mathrm{L}$ of $100 \mathrm{mM}$ phosphate buffer, $10 \mu \mathrm{L}$ of $2.5 \mathrm{mM}$ DTNB, and $20 \mu \mathrm{L}$ of $1.0 \mathrm{U} / \mathrm{mL}$ AChE solution was added to each well of a 96-well plate. The microplate was incubated at $37{ }^{\circ} \mathrm{C}$ for $10 \mathrm{~min}$, and then $40 \mu \mathrm{L}$ of 7.5 mMAtCHI was added and incubated at $37^{\circ} \mathrm{C}$ for $10 \mathrm{~min}$. The absorbance of the mixture was determined at $412 \mathrm{~nm}$ using a microplate reader instrument (Multiskan MK3, Thermo Fisher).

Cytotoxicity. The in vitro cytotoxicity of $\alpha-\mathrm{M}, \mathrm{AMG}$, and 16 derivatives of AMG was evaluated by the MTT assay in PC12 cell lines with edaravone as a positive control. All compounds were prepared by dissolving in a certain amount of DMSO and diluted with culture medium to give a single concentration of $10 \mu \mathrm{M}$. PC12 cells were seeded in 96-well plates at a density of $10^{5} /$ well and allowed to accommodate for $24 \mathrm{~h}$ in normal conditions. The cultures were then exposed to above compounds in concentrations of $10 \mu \mathrm{M}$ for $24 \mathrm{~h}$. After $24 \mathrm{~h}$, the compound-treated cells were incubated for $2 \mathrm{~h}$ with $200 \mu \mathrm{L}$ of MTT. Formazan was solubilized with $200 \mu \mathrm{L}$ of DMSO, and the absorbance of each sample was read at $490 \mathrm{~nm}$ using a microplate reader instrument. ${ }^{34}$

In Vivo Experiments. Animals. We used healthy ICR mice (18-22 g, half male and half female) for the acute toxicity assessment and adult Sprague-Dawley (SD) rats (8 weeks old, $280 \pm 10 \mathrm{~g}$ ) for the pharmacodynamic experiment of AMG-1. All animals were purchased from the Zhejiang Academy of Medical Sciences Laboratory Animal Center (license number: SCXK-20140001). All animals were housed and kept on a 12 $\mathrm{h} / 12 \mathrm{~h}$ light/dark cycle in standard conditions with temperature and relative humidity set at $23 \pm 2{ }^{\circ} \mathrm{C}$ and $55 \pm 10 \%$, respectively. All animals had free access to diet and water. Animal sacrifice at the end of the study was performed under deep anesthesia with 5\% isoflurane, and then decapitation was performed. All experimental procedures were conducted in accordance with the Guide for the Care and Use of Laboratory Animals in the Zhejiang University of Technology, Hangzhou, China, and conformed to the National Institutes of Health Guide for Care and Use of Laboratory Animals (Publication No. 85-23, revised 1996).

Acute Oral Toxicity Study. The acute toxicity test of AMG1 was performed in healthy ICR mice. ${ }^{36}$ The mice were randomly divided into seven groups (one control group and six treated groups) of 10 animals. AMG-1 was suspended in $0.5 \%$ carboxymethyl cellulose solution, and the mice were exposed to a single dose of AMG-1 1310, 1638, 2048, 2560, 3200, and $4000 \mathrm{mg} / \mathrm{kg}$ body weight by the oral gavage, which were determined through respective pretesting. Control groups were administered a $0.5 \%$ carboxymethyl cellulose solution equally. Then, mice that survived were observed for $120 \mathrm{~min}$ and once daily for the next 14 day after the treatment. The general behavior, signs of toxicity, and mortality of the mice were assessed carefully. The number of survivors after the 14 day period was noted. The toxicological effect was evaluated based on the mortality for 14 day, which was expressed by the median lethal dose value $\left(\mathrm{LD}_{50}\right)$ estimated from the regression of the log-probit mortality rate. 
Surgery and Drug Treatment. The experimental procedure for creating $\mathrm{AD}$ model rats was slightly modified from that in the previously reported study. ${ }^{37}$ In brief, $\mathrm{A} \beta_{25-35}$ was first dissolved in sterile $0.9 \%$ saline at a concentration of $5 \mu \mathrm{g} / \mu \mathrm{L}$ and incubated at $37^{\circ} \mathrm{C}$ for 4 days to allow aggregation before the hippocampal injection. Rats were weighed and general anesthetized with $5 \%$ isoflurane and fixed into a stereotaxic apparatus. A burr hole was drilled through the skull above the bilateral hippocampal coordinates (anterior-posterior $(\mathrm{AP})=$ $-3.5 \mathrm{~mm}$, medial-lateral $(\mathrm{ML})= \pm 2.5 \mathrm{~mm}$ from the bregma, and dorsal-ventral $(\mathrm{DV})=3.0 \mathrm{~mm}$ from the skull surface) according to the stereotaxic atlas. $\mathrm{A} \beta_{25-35}(2 \mu \mathrm{L}$ containing 10 $\mu \mathrm{g}$ ) was subsequently injected over $5 \mathrm{~min}$ through a microsyringe into the hole. The needle was left for an additional $5 \mathrm{~min}$ before the withdrawal. Sham-vehicle rats underwent the same surgical procedure, except that normal saline (as a vehicle of $\mathrm{A} \beta_{25-35}$ ) was bilaterally injected. After 1 day of $\mathrm{A} \beta_{25-35}$ hippocampal injection, all operated rats were randomly divided into six groups $(n=20)$ and administered orally different drug treatments once daily for 30 days (for experimental schedules, see Supporting Figure 1): sham control group (vehicle only), positive group $(1 \mathrm{mg} / \mathrm{kg}$ donepezil), $\mathrm{A} \beta_{25-35}$-induced model group (vehicle only), $\mathrm{A} \beta_{25-35}+$ AMG-1 $5 \mathrm{mg} / \mathrm{kg}$ group, $\mathrm{A} \beta_{25-35}+\mathrm{AMG}-110 \mathrm{mg} /$ $\mathrm{kg}$ group, and $\mathrm{A} \beta_{25-35}+\mathrm{AMG}-120 \mathrm{mg} / \mathrm{kg}$ group.

Open-Field Test for the Locomotor Ability. After AMG-1 administration for 30 days, rats were subjected to an open-field test to evaluate the exploratory activity and locomotor ability. ${ }^{38}$ The open-field apparatus was a clear cubic box with a Plexiglas floor, was $100 \times 100 \times 50 \mathrm{~cm}^{3}$ in size (BW-OF362, Shanghai, China), and was dimly illuminated during the test. After $1 \mathrm{~h}$ of acclimation in the dim room, each rat was placed in the same place of the open arena and allowed to freely explore for $2 \mathrm{~min}$. The floor and walls were cleaned with $70 \%$ ethanol to eliminate the odor between each trial. The rats' behavior was recorded by a video digital recorder suspended $1.8 \mathrm{~m}$ above the area. The locomotor activity was analyzed by the total distance traveled $(\mathrm{m})$.

Morris Water Maze. The spatial learning and memory ability of all rats was tested by the Morris water maze (XRXM101, Shanghai, China). ${ }^{39}$ Briefly, a circular pool $(180 \mathrm{~cm}$ in diameter and $60 \mathrm{~cm}$ in depth) was filled with water and maintained at $25 \pm 1{ }^{\circ} \mathrm{C}$. Animals were trained to seek an escape platform $\left(25 \mathrm{~cm}^{2}\right.$ Plexiglas square, $2 \mathrm{~cm}$ below the surface of the water in one of the four quadrants) with four trials for 2 min per trial with a $30 \mathrm{~min}$ interval between the trials, daily, for 5 consecutive days. On locating the platform, the rat was allowed to remain there for $30 \mathrm{~s}$ before being returned to its cage. If the rat did not find the platform within 2 min, the time was recorded as $2 \mathrm{~min}$. The rat was then manually guided to the platform where it stayed for $30 \mathrm{~s}$. The escape latency and swim pattern were measured by a video tracking system for the analysis of performance. After completion of the escape latency test, rats were subjected to a probe trial in which the platform was removed from the pool and replaced by a visible platform. Rats were placed in the pool at the same pole and allowed to swim for $2 \mathrm{~min}$. The number of rats crossing the target quadrant was recorded.

Tissue Preparation. On the terminal day, the rats were deeply anesthetized with $5 \%$ isoflurane. The whole brains of eight rats were isolated after performing intracardiac perfusion with $100 \mathrm{mmol} / \mathrm{L}$ phosphate-buffered saline (PBS). Then, the brains were quickly removed and the brain tissues were fixed in
$10 \%$ neutral buffered formalin, dehydrated, and embedded in paraffin for coronal microtome sections with hematoxylin staining and Bielschowsky silver staining. Similarly, the whole brains of six rats perfused with PBS, followed by ice-cold $4 \%$ paraformaldehyde, were sectioned into $30 \mu \mathrm{m}$ slices for immunohistochemical staining. The remaining brains of the rats were isolated and postfixed in $50 \mathrm{mmol} / \mathrm{L}$ PBS containing $4 \%$ paraformaldehyde overnight, immersed in a solution containing $30 \%$ sucrose in $50 \mathrm{mmol} / \mathrm{L} \mathrm{PBS}$, and stored at 4 ${ }^{\circ} \mathrm{C}$ until sectioning. The frozen brains were sectioned by a freezing microtome (Thermo Fisher) at $25 \mu \mathrm{m}$ for Nissl staining.

Hematoxylin and Eosin (HE) Staining. After animal behavior test experiments, four rats in each group were chosen randomly to be sacrificed. Their brains were quickly removed and fixed in $4 \%$ formalin. The brains were then dehydrated in alcohol and embedded in paraffin for coronal microtome sections ( $5 \mu \mathrm{m}$ thick) with HE staining for histomorphological study under the light microscope $\left(200 \times\right.$, Nikon, Japan). ${ }^{40}$

Niss/ Staining. Hippocampi of brain tissues of six rats were cut into $25 \mu \mathrm{m}$ thick sections by a freezing microtome (Thermo Fisher) and series stained using a Nissl staining solution (Beyotime Institute of Biotechnology, Nangtong, China) according to the manufacturer's instructions. In brief, the sections were mounted onto gelatin-coated slides. After being dipped in $98 \% \mathrm{EtOH}$ for 2 min, slides were immersed in xylene for $2 \mathrm{~min}$ and rehydrated in a series of concentrations of EtOH from 98 to 70 to 50 to 20 to $0 \%$ (distilled water) for 2 min each. Sections were then stained with $2 \%$ cresyl violet for 5 min. After two dips in distilled water, sections were dehydrated with a series of concentrations of EtOH from 50 to 70 to $98 \%$ and then were cleaned in xylene and mounted with Permount. At the end of staining, the neuronal survival and loss of Nissl bodies in the hippocampus were observed using light microscopy (Nikon, Japan). ${ }^{41}$

Bielschowsky Silver Staining. Bielschowsky silver staining was used to assess the $\mathrm{A} \beta$ plaques and neurofibrillary tangles (NFTs), the hallmark lesions of $\mathrm{AD}$. Representative tissue sections were stained by a modified Bielschowsky method. ${ }^{42}$ Briefly, coronal brain sections $(40 \mu \mathrm{m})$ were cut with the microtome, and the rehydrated sections were covered with $20 \% \mathrm{AgNO}_{3}$ in the dark for $20 \mathrm{~min}$, followed by rinsing in distilled water and incubation in the ammoniacal silver solution for $10 \mathrm{~min}$ in the dark. After the incubation, the slides were immersed in ammoniated water and developed. Finally, sections were rinsed, dehydrated, cleared, and coverslipped. Positive silver-stained neurons were counted and photographed under $10 \times 40$ magnification with light microscopy (Nikon, Japan).

Immunohistochemistry Analysis for $A \beta_{1-42}$. Immunohistochemistry for $\mathrm{A} \beta_{1-42}$ was performed as described. ${ }^{43}$ Briefly, hippocampal sections of five rats were deparaffinized in xylene and hydrated through graded alcohol. Endogenous peroxidase was blocked with $3 \%$ hydroxide in $10 \%$ methanol. Then, sections were incubated in blocking serum, 5\% normal goat serum in $0.3 \%$ Triton with PBS. Subsequently, sections were incubated in a primary antibody anti-A $\beta_{1-42}$ (rabbit anti-rat amyloid $\beta$ protein 1-42 monoclonal antibody 1:300 dilution, Dakopatts A/C; Bioss China) solution overnight at $4{ }^{\circ} \mathrm{C}$. Sections were washed in PBS with $0.3 \%$ Triton X-100 and incubated in a secondary antibody (biotinylated goat antirabbit antibody, 1:500) solution for $1 \mathrm{~h}$ at room temperature, which was followed by washing and staining with DAB 
(1:1000) for another $10 \mathrm{~min}$ at room temperature. Stained sections were mounted on resin-coated slides and dried. Photomicrographs of brain sections were taken using a digital camera (Nikon, Japan), and at least 20 fields from each brain section were analyzed using the Image $\mathrm{J}$ software.

Chemogenomics Databases and Tools. Chemogenomics Database for Alzheimer's Disease (http://www.cbligand.org/ $\mathrm{AD} /),{ }^{44}$ Chemogenomics Database for Drug Abuse Research (http://www.cbligand.org/CDAR/), ${ }^{45}$ and Chemogenomics Database for Cardiovascular Disease (http://www.cbligand. org $/ \mathrm{CVD} /)^{46}$ were combined for the target prediction on $\alpha$ mangostin and AMG-1. Two chemogenomics tools, TargetHunter $^{47}$ and HTDocking, ${ }^{48}$ were used specifically for the identification of both therapeutic targets and off-target interactions. The inquiry compounds were $\alpha$-mangostin (1,3,6-trihydroxy-7-methoxy-2,8-bis(3-methylbut-2-en-1-yl)9H-xanthen-9-one) and AMG-1 (5-hydroxy-8-methoxy-2,2dimethyl-7-(3-methylbut-2-en-1-yl)-6-oxo-2H,6H-pyrano[3,2b] xanthen-9-yl methyl(phenyl)carbamate). For TargetHunter, the fingerprint type was set to be extended-connectivity fingerprints 6 (ECFP6). ${ }^{49,50}$ The threshold for 2D similarity was set to be $60 \%$. For HTDocking, high-throughput molecular docking studies were performed between the inquired compounds and protein targets in each database. Networks were constructed using Cytoscape. ${ }^{51}$ Both the in silico prediction and the reported experimental validations were combined. The layout format was set to the degree-sorted circle.

Blood-Brain Barrier (BBB) Prediction, PAINS-Remover, and Toxtree. The BBB Prediction Server (http://www. cbligand.org/BBB $/)^{44,52}$ was used for the in silico evaluation of whether the inquired compounds can pass the BBB. For each compound, four fingerprint types, MACCS, Openbabel (FP2), Molprint 2D, and PubChem, were applied. For each fingerprint type, two algorithms, AdaBoost and SVM, were adapted. A total of eight combinations of fingerprints and algorithms were calculated for both $\alpha$-mangostin and AMG-1.

PAINS-Remover (http://www.cbligand.org/PAINS/) ${ }^{53}$ was used to detect and remove the pan-assay interference compounds (PAINS). Both $\alpha$-mangostin and AMG-1 were analyzed to identify the existence of the undesired substructural features.

Toxtree (http://toxtree.sourceforge.net/index.html) ${ }^{54}$ was used to estimate any toxic hazard by applying a tree approach. The SMILES formats of $\alpha$-mangostin and AMG-1 functioned as the input. Three levels, low (Class I), intermediate (Class II), and high (Class III), of estimated toxic hazards were reported.

Statistical Analysis. Data were analyzed using one-way ANOVA, followed by the least significant difference post-hoc tests or the independent samples $t$-tests. The results are expressed as mean \pm SEM. Differences between groups were considered statistically significant when $P<0.05$. All statistical analyses were performed using the SPSS 19.0 software (SPSS Inc; 19.0).

\section{ASSOCIATED CONTENT}

\section{SI Supporting Information}

The Supporting Information is available free of charge at https://pubs.acs.org/doi/10.1021/acsomega.0c00057.
Animal study timeline (Figure S1); ${ }^{1} \mathrm{H}$ and ${ }^{13} \mathrm{C}$ NMR spectra of all of the reported synthesized compounds (Figures S2-S33) (PDF)

\section{AUTHOR INFORMATION}

\section{Corresponding Author}

Zha-Jun Zhan - College of Pharmacology Sciences Zhejiang University of Technology, Hangzhou 310014, P. R. China; (1) orcid.org/0000-0001-7865-5435; Phone: 86(571)88871075; Email: zjnpr@zjut.edu.cn

\section{Authors}

Yan Chen - College of Pharmacology Sciences Zhejiang University of Technology, Hangzhou 310014, P. R. China; Department of Pharmaceutical Sciences and Computational Chemical Genomics Screening Center, School of Pharmacy and NIH National Center of Excellence for Computational Drug Abuse Research, University of Pittsburgh, Pittsburgh, Pennsylvania 15261, United States

Yuemin Bian - Department of Pharmaceutical Sciences and Computational Chemical Genomics Screening Center, School of Pharmacy and NIH National Center of Excellence for Computational Drug Abuse Research, University of Pittsburgh, Pittsburgh, Pennsylvania 15261, United States

Jian-Wei Wang - College of Pharmacology Sciences Zhejiang University of Technology, Hangzhou 310014, P. R. China

Ting-Ting Gong - College of Pharmacology Sciences Zhejiang University of Technology, Hangzhou 310014, P. R. China

You-Min Ying - College of Pharmacology Sciences Zhejiang University of Technology, Hangzhou 310014, P. R. China; (1) orcid.org/0000-0002-2231-5068

Lie-Feng Ma - College of Pharmacology Sciences Zhejiang University of Technology, Hangzhou 310014, P. R. China; - orcid.org/0000-0001-7711-0767

Wei-Guang Shan - College of Pharmacology Sciences Zhejiang University of Technology, Hangzhou 310014, P. R. China

Xiang-Qun Xie - Department of Pharmaceutical Sciences and Computational Chemical Genomics Screening Center, School of Pharmacy, NIH National Center of Excellence for Computational Drug Abuse Research, Drug Discovery Institute, and Departments of Computational Biology and Structural Biology, School of Medicine, University of Pittsburgh, Pittsburgh, Pennsylvania 15261, United States; 10 orcid.org/0000-00026881-6175

Complete contact information is available at:

https://pubs.acs.org/10.1021/acsomega.0c00057

\section{Author Contributions}

\#Y.C. and Y.B. contributed equally to this work.

\section{Notes}

The authors declare no competing financial interest.

\section{ACKNOWLEDGMENTS}

This work was done while Dr. Y.C. was a visiting scholar at the University of Pittsburgh (9/30/2017-9/28/2018). The experimental work was completed in Chen and Zhan's Laboratory, while the computational work was finished in Xie's Center/Laboratory. The authors would like to acknowledge the funding support to the Xie laboratory from the NIH NIDA (P30 DA035778A1 to X.-Q.X.) and the funding support to the Zhan laboratory from the National Natural Science Foundation of China (81872777 to Z.-J.Z.). 


\section{REFERENCES}

(1) Singh, S. K.; Srivastav, S.; Yadav, A. K.; Srikrishna, S.; Perry, G. Overview of Alzheimer's disease and some therapeutic approaches targeting $\mathrm{A} \beta$ by using several synthetic and herbal compounds. Oxid. Med. Cell. Longevity 2016, 2016, No. 7361613.

(2) Puzzo, D.; Lee, L.; Palmeri, A.; Calabrese, G.; Arancio, O. Behavioral assays with mouse models of Alzheimer's disease: practical considerations and guidelines. Biochem. Pharmacol. 2014, 88, 450467.

(3) Reid, G. A.; Darvesh, S. Butyrylcholinesterase-knockout reduces brain deposition of fibrillar $\beta$-amyloid in an Alzheimer mouse model. Neuroscience 2015, 298, 424-435.

(4) Zheng, K.; Dai, X.; Xiao, N.; Wu, X.; Wei, Z.; Fang, W.; Zhu, Y.; Zhang, J.; Chen, $\mathrm{X}$. Curcumin ameliorates memory decline via inhibiting BACE1 expression and $\beta$-Amyloid pathology in $5 \times \mathrm{FAD}$ transgenic mice. Mol. Neurobiol. 2017, 54, 1967-1977.

(5) Kasza, Á.; Penke, B.; Frank, Z.; Bozsó, Z.; Szegedi, V.; Hunya, Á.; Németh, K.; Kozma, G.; Fülöp, L. Studies for improving a rat model of Alzheimer's disease: icv administration of well-characterized $\beta$-amyloid 1-42 oligomers induce dysfunction in spatial memory. Molecules 2017, 22, 2007.

(6) De Strooper, B. Proteases and proteolysis in Alzheimer disease: a multifactorial view on the disease process. Physiol. Rev. 2010, 90, 465-494.

(7) D'amelio, M.; Rossini, P. M. Brain excitability and connectivity of neuronal assemblies in Alzheimer's disease: from animal models to human findings. Prog. Neurobiol. 2012, 99, 42-60.

(8) Zhang, Z.-X.; Li, Y.-B.; Zhao, R.-P. Epigallocatechin gallate attenuates $\beta$-Amyloid generation and oxidative stress involvement of PPAR $\gamma$ in N2a/APP695 cells. Neurochem. Res. 2017, 42, 468-480.

(9) Lee, J. H.; Jeong, S. K.; Kim, B.; Park, K.; Dash, A. Donepezil across the spectrum of Alzheimer's disease: dose optimization and clinical relevance. Acta Neurol. Scand. 2015, 131, 259-267.

(10) Yatabe, Y.; Hashimoto, M.; Kaneda, K.; Honda, K.; Ogawa, Y.; Yuuki, S.; Ikeda, M. Efficacy of increasing donepezil in mild to moderate Alzheimer's disease patients who show a diminished response to $5 \mathrm{mg}$ donepezil: a preliminary study. Psychogeriatrics 2013, 13, 88-93.

(11) Cummings, J.; Lai, T. J.; Hemrungrojn, S.; Mohandas, E.; Yun Kim, S.; Nair, G.; Dash, A. Role of donepezil in the management of neuropsychiatric symptoms in Alzheimer's disease and dementia with Lewy bodies. CNS Neurosci. Ther. 2016, 22, 159-166.

(12) Wang, X.; Wu, J.; Yu, C.; Tang, Y.; Liu, J.; Chen, H.; Jin, B.; Mei, Q.; Cao, S.; Qin, D. Lychee seed saponins improve cognitive function and prevent neuronal injury via inhibiting neuronal apoptosis in a rat model of Alzheimer's disease. Nutrients 2017, 9, 105.

(13) Lin, N.; Pan, X.-D.; Chen, A.-Q.; Zhu, Y.-G.; Wu, M.; Zhang, J.; Chen, X.-C. Tripchlorolide improves age-associated cognitive deficits by reversing hippocampal synaptic plasticity impairment and NMDA receptor dysfunction in SAMP8 mice. Behav. Brain Res. 2014, 258, $8-$ 18.

(14) Zhang, S.-Y.; Zhan, Z. J.; Zhang, H.; Qi, H.; Zhang, L.-Q.; Chen, S.-X.; Gan, L.-S.; Wang, J.-D.; Ma, L.-F. Morindolestatin, naturally occurring dehydromorpholinocarbazolealkaloid from soilderived bacterium of the genus Streptomyces. Org. Lett. 2020, 22, $1113-1116$

(15) Choi, J. G.; Kim, S. Y.; Kim, J. W.; Oh, M. S. OptimizedSopungSunkiwon, a herbal formula, attenuates $\mathrm{A} \beta$ oligomer-induced neurotoxicity in Alzheimer's disease models. J. Evidence-Based Complementary Altern. Med. 2017, 2017, No. 7601486

(16) Catorce, M. N.; Acero, G.; Pedraza-Chaverri, J.; Fragoso, G.; Govezensky, T.; Gevorkian, G. Alpha-mangostin attenuates brain inflammation induced by peripheral lipopolysaccharide administration in C57BL/6J mice. J. Neuroimmunol. 2016, 297, 20-27.

(17) Tewtrakul, S.; Wattanapiromsakul, C.; Mahabusarakam, W. Effects of compounds from Garcinia mangostana on inflammatory mediators in RAW264. 7 macrophage cells. J. Ethnopharmacol. 2009, 121, 379-382.
(18) Devi Sampath, P.; Vijayaraghavan, K. Cardioprotective effect of $\alpha$-mangostin, a xanthone derivative from mangosteen on tissue defense system against isoproterenol-induced myocardial infarction in rats. J. Biochem. Mol. Toxicol. 2007, 21, 336-339.

(19) Gutierrez-Orozco, F.; Chitchumroonchokchai, C.; Lesinski, G. B.; Suksamrarn, S.; Failla, M. L. $\alpha$-Mangostin: anti-inflammatory activity and metabolism by human cells. J. Agric. Food Chem. 2013, 61 , 3891-3900.

(20) Kaomongkolgit, R.; Jamdee, K.; Chaisomboon, N. Antifungal activity of alpha-mangostin against Candida albicans. J. Oral Sci. 2009, 51, 401-406.

(21) Obolskiy, D.; Pischel, I.; Siriwatanametanon, N.; Heinrich, M. Garcinia mangostana L.: a phytochemical and pharmacological review. Phytother. Res. 2009, 23, 1047-1065.

(22) Williams, P.; Ongsakul, M.; Proudfoot, J.; Croft, K.; Beilin, L. Mangostin inhibits the oxidative modification of human low density lipoprotein. Free Radical Res. 1995, 23, 175-184.

(23) Pedraza-Chaverri, J.; Cárdenas-Rodríguez, N.; Orozco-Ibarra, M.; Pérez-Rojas, J. M. Medicinal properties of mangosteen (Garcinia mangostana). Food Chem. Toxicol. 2008, 46, 3227-3239.

(24) Sattayasai, J.; Chaonapan, P.; Arkaravichie, T.; Soi-ampornkul, R.; Junnu, S.; Charoensilp, P.; Samer, J.; Jantaravinid, J.; Masaratana, P.; Suktitipat, B.; et al. Protective effects of mangosteen extract on $\mathrm{H}_{2} \mathrm{O}_{2}$-induced cytotoxicity in SK-N-SH cells and scopolamineinduced memory impairment in mice. PLoS One 2013, 8, No. e85053.

(25) Johnson, J. J.; Petiwala, S. M.; Syed, D. N.; Rasmussen, J. T.; Adhami, V. M.; Siddiqui, I. A.; Kohl, A. M.; Mukhtar, H. $\alpha$ Mangostin, a xanthone from mangosteen fruit, promotes cell cycle arrest in prostate cancer and decreases xenograft tumor growth. Carcinogenesis 2012, 33, 413-419.

(26) Hafeez, B. B.; Mustafa, A.; Fischer, J. W.; Singh, A.; Zhong, W.; Shekhani, M. O.; Meske, L.; Havighurst, T.; Kim, K.; Verma, A. K. $\alpha$ Mangostin: a dietary antioxidant derived from the pericarp of Garcinia mangostana L. inhibits pancreatic tumor growth in xenograft mouse model. Antioxid. Redox Signaling 2014, 21, 682-699.

(27) Wang, Y.; Xia, Z.; Xu, J.-R.; Wang, Y.-X.; Hou, L.-N.; Qiu, Y.; Chen, H.-Z. $\alpha$-Mangostin, a polyphenolic xanthone derivative from mangosteen, attenuates $\beta$-amyloid oligomers-induced neurotoxicity by inhibiting amyloid aggregation. Neuropharmacology 2012, 62, 871881 .

(28) Bian, Y.-M.; He, X.-B.; Jing, Y.-K.; Wang, L.-R.; Wang, J.-M.; Xie, X.-Q. Computational systems pharmacology analysis of cannabidiol: a combination of chemogenomics-knowledgebase network analysis and integrated in silico modeling and simulation. Acta Pharmacol. Sin. 2019, 40, 374-386.

(29) Pinto, M.; Castanheiro, R. Synthesis of prenylated xanthones: An overview. Curr. Org. Chem. 2009, 13, 1215-1240.

(30) Yu, Q.-S.; Holloway, H. W.; Flippen-Anderson, J. L.; Hoffman, B.; Brossi, A.; Greig, N. H. Methyl analogues of the experimental Alzheimer drug phenserine: synthesis and structure/activity relationships for acetyl-and butyrylcholinesterase inhibitory action. J. Med. Chem. 2001, 44, 4062-4071.

(31) Luo, W.; Yu, Q.-S.; Kulkarni, S. S.; Parrish, D. A.; Holloway, H. W.; Tweedie, D.; Shafferman, A.; Lahiri, D. K.; Brossi, A.; Greig, N. $\mathrm{H}$. Inhibition of human acetyl-and butyrylcholinesterase by novel carbamates of (-)-and (+)-tetrahydrofurobenzofuran and methanobenzodioxepine. J. Med. Chem. 2006, 49, 2174-2185.

(32) Shaw, K. T.; Utsuki, T.; Rogers, J.; Yu, Q. S.; Sambamurti, K.; Brossi, A.; Ge, Y. W.; Lahiri, D. K.; Greig, N. H. Proc. Natl. Acad. Sci. U.S.A. 2001, 98, 7605-7610.

(33) Ying, Y.-M.; Yu, K.-M.; Lin, T.-S.; Ma, L.-F.; Fang, L.; Yao, J.B.; Chen, B.-Y.; Wang, R.-W.; Shan, W.-G.; Wang, Z.; Zhan, Z.-J. Antiproliferative prenylated xanthones from the pericarps of Garcinia mangostana. Chem. Nat. Compd. 2017, 53, 555-556.

(34) Srividhya, R.; Kalaiselvi, P. Neuroprotective potential of epigallo catechin-3-gallate in PC-12 cells. Neurochem. Res. 2013, 38, 486-493.

(35) Zhao, H.; Zhou, S.; Zhang, M.; Feng, J.; Wang, S.; Wang, D.; Geng, Y.; Wang, X. An in vitro AChE inhibition assay combined with 
UF-HPLC-ESI-Q-TOF/MS approach for screening and characterizing of AChE inhibitors from roots of Coptis chinensis Franch. J. Pharm. Biomed. Anal. 2016, 120, 235-240.

(36) Wan, D.; Zhou, X.; Xie, C.; Shu, X.; Wu, X.; Yin, Y. Toxicological evaluation of ferrous $\mathrm{N}$-carbamylglycinate chelate: acute, sub-acute toxicity and mutagenicity. Regul. Toxicol. Pharmacol. 2015, 73, 644-651.

(37) Zhang, Q.; Li, J.; Liu, C.; Song, C.; Li, P.; Yin, F.; Xiao, Y.; Li, J.; Jiang, W.; Zong, A.; Zhang, X.; Wang, F. Protective effects of low molecular weight chondroitin sulfate on amyloid beta (Abeta)induced damage in vitro and in vivo. Neuroscience 2015, 305, 169182.

(38) Amiri, S.; Haj-Mirzaian, A.; Momeny, M.; Amini-Khoei, H.; Rahimi-Balaei, M.; Poursaman, S.; Rastegar, M.; Nikoui, V.; Mokhtari, T.; Ghazi-Khansari, M.; Hosseini, M. J. Streptozotocin induced oxidative stress, innate immune system responses and behavioral abnormalities in male mice. Neuroscience 2017, 340, 373-383.

(39) Mohammadi-Farani, A.; Haghighi, A.; Ghazvineh, M. Effects of long term administration of testosterone and estradiol on spatial memory in rats. Res. Pharm. Sci. 2015, 10, 407-418.

(40) Jayant, S.; Sharma, B. M.; Sharma, B. Protective effect of transient receptor potential vanilloid subtype 1 (TRPV1) modulator, against behavioral, biochemical and structural damage in experimental models of Alzheimer's disease. Brain Res. 2016, 1642, 397-408.

(41) Xu, K.; Zhang, Y.; Wang, Y.; Ling, P.; Xie, X.; Jiang, C.; Zhang, $\mathrm{Z}$.; Lian, X. Y. Ginseng $\mathrm{Rb}$ fraction protects glia, neurons and cognitive function in a rat model of neurodegeneration. PLoS One 2014, 9, No. e101077.

(42) Litchfield, S.; Nagy, Z. New temperature modification makes the Bielschowsky silver stain reproducible. Acta Neuropathol. 2001, $101,17-21$.

(43) Clifford, P. M.; Zarrabi, S.; Siu, G.; Kinsler, K. J.; Kosciuk, M. C.; Venkataraman, V.; D’Andrea, M. R.; Dinsmore, S.; Nagele, R. G. Abeta peptides can enter the brain through a defective blood-brain barrier and bind selectively to neurons. Brain Res. 2007, 1142, 223236.

(44) Liu, H.; Wang, L.; Lv, M.; Pei, R.; Li, P.; Pei, Z.; Wang, Y.; Su, W.; Xie, X. Q. AlzPlatform: an Alzheimer's disease domain-specific chemogenomics knowledgebase for polypharmacology and target identification research. J. Chem. Inf. Model 2014, 54, 1050-1060.

(45) Xie, X.-Q.; Wang, L.; Liu, H.; Ouyang, Q.; Fang, C.; Su, W. Chemogenomics knowledgebased polypharmacology analyses of drug abuse related G-protein coupled receptors and their ligands. Front. Pharmacol. 2014, 5, 1-11.

(46) Zhang, H.; Ma, S.; Feng, Z.; Wang, D.; Li, C.; Cao, Y.; Chen, X.; Liu, A.; Zhu, Z.; Zhang, J.; Zhang, G.; Chai, Y.; Wang, L.; Xie, X. Q. Cardiovascular disease chemogenomics knowledgebase-guided target identification and drug synergy mechanism study of an herbal formula. Sci. Rep. 2016, 6, No. 33963.

(47) Wang, L.; Ma, C.; Wipf, P.; Liu, H.; Su, W.; Xie, X. Q. TargetHunter: an in silico target identification tool for predicting therapeutic potential of small organic molecules based on chemogenomic database. AAPS J. 2013, 15, 395-406.

(48) Bian, Y.; Feng, Z.; Yang, P.; Xie, X. Q. Integrated in silico fragment-based drug design: case study with allosteric modulators on metabotropic glutamate receptor 5. AAPS J. 2017, 19, 1235-1248.

(49) Bian, Y.; Jing, Y.; Wang, L.; Ma, S.; Jun, J. J.; Xie, X. Q. Prediction of orthosteric and allosteric regulations on cannabinoid receptors using supervised machine learning classifiers. Mol. Pharmaceutics 2019, 16, 2605-2615.

(50) Bian, Y.; Wang, J.; Jun, J. J.; Xie, X. Q. Deep convolutional generative adversarial network (dcGAN) models for screening and design of small molecules targeting cannabinoid receptors. Mol. Pharmaceutics 2019, 16, 4451-4460.

(51) Smoot, M. E.; Ono, K.; Ruscheinski, J.; Wang, P. L.; Ideker, T. Cytoscape 2.8: new features for data integration and network visualization. Bioinformatics 2011, 27, 431-432.

(52) Bian, Y.; Xie, X. S. Computational fragment-based drug design: current trends, strategies, and applications. AAPS J. 2018, 20, 59-81.
(53) Baell, J. B.; Holloway, G. A. New substructure filters for removal of pan assay interference compounds (PAINS) from screening libraries and for their exclusion in bioassays. J. Med. Chem. 2010, 53, 2719-2740.

(54) Patlewicz, G.; Jeliazkova, N.; Safford, R. J.; Worth, A. P.; Aleksiev, B. An evaluation of the implementation of the Cramer classification scheme in the Toxtree software. SAR QSAR Environ. Res. 2008, 19, 495-524. 